\title{
Inorganic nanomaterial lubricant additives for base fluids, to improve tribological performance: Recent developments
}

\author{
Junhai WANG ${ }^{1,2}$, Weipeng ZHUANG ${ }^{1}$, Wenfeng LIANG ${ }^{1}$, Tingting YAN ${ }^{1}$, Ting LI $^{1}$, Lixiu ZHANG ${ }^{1}$, Shu LI $^{2, *}$ \\ ${ }^{1}$ School of Mechanical Engineering, Shenyang Jianzhu University, Shenyang 110168, China \\ ${ }^{2}$ Institute of Metal Research, Chinese Academy of Sciences, Shenyang 110016, China \\ Received: 13 January 2021 / Revised: 10 March 2021 / Accepted: 19 March 2021 \\ (C) The author(s) 2021.
}

\begin{abstract}
In this paper, we review recent research developments regarding the tribological performances of a series of inorganic nano-additives in lubricating fluids. First, we examine several basic types of inorganic nanomaterials, including metallic nanoparticles, metal oxides, carbon nanomaterials, and "other" nanomaterials. More specifically, the metallic nanoparticles we examine include silver, copper, nickel, molybdenum, and tungsten nanoparticles; the metal oxides include $\mathrm{CuO}, \mathrm{ZnO}, \mathrm{Fe}_{3} \mathrm{O}_{4}, \mathrm{TiO}_{2}, \mathrm{ZrO}_{2}, \mathrm{Al}_{2} \mathrm{O}_{3}$, and several double-metal oxides; the carbon nanomaterials include fullerene, carbon quantum dots, carbon nanotubes, graphene, graphene oxides, graphite, and diamond; and the "other" nanomaterials include metal sulfides, rare-earth compounds, layered double hydroxides, clay minerals, hexagonal boron nitride, black phosphorus, and nanocomposites. Second, we summarize the lubrication mechanisms of these nano-additives and identify the factors affecting their tribological performance. Finally, we briefly discuss the challenges faced by inorganic nanoparticles in lubrication applications and discuss future research directions. This review offers new perspectives to improve our understanding of inorganic nano-additives in tribology, as well as several new approaches to expand their practical applications.
\end{abstract}

Keywords: antifriction mechanism; inorganic additives; nanomaterials; tribological performances

\section{Introduction}

Friction and wear can result in energy wastage, material losses, and shorter service lives of the moving parts within mechanical systems. It has been demonstrated that $\sim 23 \%$ of total fuel energy losses is directly attributable to the tribological contact [1]. Because of its capacity to save energy and protect mechanical components, lubrication has been proven as an efficient means of decreasing friction and wear across many industrial applications. Commercial lubricants (e.g., those used in automotive and high-performance aerospace engines) involve complicated preparation procedures, because they contain base oils and various additives. To satisfy the sustainability requirements (i.e., maximized fuel efficiency and minimized pollution), the development of efficient lubricant additives has received considerable attention from both industry and academia.

The evolution of nanotechnology has led to the development of nanomaterials. As a novel class of materials, nanomaterials have found broad applicability across numerous technological fields. Studies have been conducted on a wide variety of nanomaterials and compounds thereof (especially inorganic nanomaterials), to investigate their potential as lubricant additives. Recent advances in lubrication research have revealed that many inorganic nano-additives provide excellent lubrication performance. In recent years, pure metal nanoparticles [2] and their combinations [3], metal oxides [4-6], sulfides [7-9], layered silicates [10], and carbon nanomaterials $[11,12]$ have increasingly been

* Corresponding author: Shu LI, E-mail: shuli@imr.ac.cn 
used in tribological applications. The increased tendency toward utilizing nanoparticles as lubricant additives is attributed to their excellent properties. With their small sizes $(2-100 \mathrm{~nm})$, nanoparticles can easily penetrate into the friction area and fill the microroughness. This helps prevent the surfaces of the friction pair from directly contacting each other. Owing to their high surface energies, nanoparticles can easily precipitate or generate protective films on the friction surface [13]; they can also have a mending or self-repairing effect on worn surfaces.

Different additives exhibit different characteristics and enhance the tribological performance of lubricants in various ways. The improvements that nano-additives realize in the tribological performances of lubricants can be interpreted via the rolling-slip effect, the generation of a third body between the rubbing details, the formation of a tribo-film in the friction zone, and variations in the lubricants' rheological performances [14]. They can also be used for polishing friction surfaces and smoothing abrasive wear [15]. Therefore, we provide a comprehensive review of different varieties of inorganic lubricant additives and their anti-friction mechanisms. A summary of the inorganic nanomaterials used as lubricant additives in base fluids is presented in Fig. 1.

\section{Metallic nanoparticles}

Metallic nanoparticles (e.g., $\mathrm{Ag}, \mathrm{Cu}, \mathrm{Ni}, \mathrm{Mo}$, and $\mathrm{W}$ ) offer several unique advantages [16]: (1) They can form softer and more compliant nanoparticle-containing layers through being physically pressed and/or smeared into the contact area; this layer facilitates deformation and faster running-in with greater conformal contact, thereby realizing reduced asperity contact pressure and shear resistance under lower friction; furthermore, they offer a cushion that absorbs a portion of the asperity collision force, thereby reducing noise. (2) They can participate in tribo-film formation in two ways: via tribochemical reactions or by acting as a metal cation supply.

\subsection{Silver nanoparticles}

Silver nanoparticles have attracted considerable interest owing to their environmental friendliness, chemical

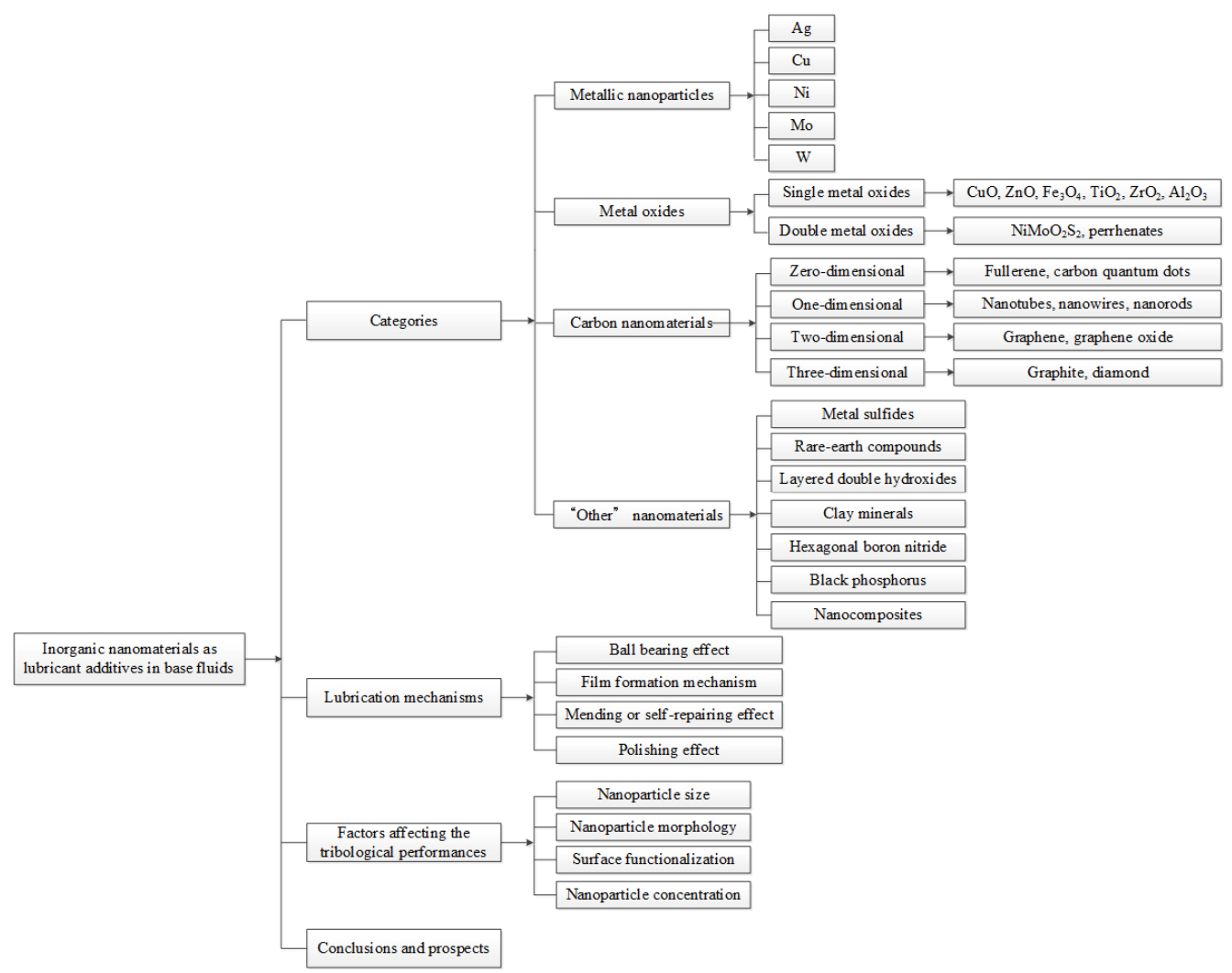

Fig. 1 Summary of inorganic nanomaterials as lubricant additives in base fluids. 
stability, low shear strength, reliable embeddability, ductility, and considerable potential for improving friction reduction, and anti-wear characteristics [16-19]. Therefore, many scholars have attempted to use silver nanoparticles as lubricant additives, to improve the lubrication performance of base fluids, particularly oil-based lubricants. Kumara et al. [16] synthesized and characterized two types of oil-soluble silver nanoparticles and evaluated their potential as lubricant additives. It was found that using $\mathrm{Ag}$ nanoparticles in base oils could reduce friction by $35 \%$ and result in $85 \%$ less wear in boundary lubrication applications. A nano-lubricant containing silver nanoparticles suspended in polyethylene glycol (PEG) was synthesized and investigated by Ghaednia et al. [18]. As revealed by a series of frictional, wear, and rheological analyses, as well as Stribeck curve analysis, adding a small quantity of $\mathrm{Ag}$ nanoparticles helped to reduce both friction and wear. More specifically, when participating in a mixed lubrication regime, silver nanoparticles can realize a $35 \%$ decrease in the coefficient of friction (COF) and wear scar diameter (WSD). Moreover, reducing the real area of contact has been recognized as a key lubrication mechanism for nanoparticle additives.

Previous studies have highlighted Ag nanoparticles as promising candidates for lubricant additives. However, when applied for lubrication, Ag nanoparticles exhibit abundant surface activity and inadequate compatibility with base fluids; this leads to oxidation, coacervation, and precipitation in the base fluids, which subsequently impairs the lubrication performance of the Ag nanoparticles. Other disadvantages of $\mathrm{Ag}$ include its high cost and tendency to form surface compounds such as sulfides, which can degrade its tribological performance. To overcome these challenges in the application of silver nanoparticles to lubrication, surface modification can be employed to convert silver nanoparticles into organic miscible nanoparticles, to enhance the oil's solubility; the feasibility of this approach has been demonstrated in previous studies [17].

\subsection{Copper nanoparticles}

Copper has been widely applied both as a solid lubricating material and in the fabrication of polymer- based self-lubricating fillers, owing to its high ductility, low hardness, and ideal shear strength. Nanostructured copper materials preserve most of the excellent properties of copper and are also endowed with unique properties through the nano-size effect. Copper nanoparticles exhibit a significantly decreased melting point, and their chemical reactivity is increased significantly by the small-size effect of nanomaterials. When used as additives for lubrication, copper nanoparticles tend to melt on the contact interface after stimulation from the heat generated during frictional and tribochemical reaction processes; consequently, a micro-solid solution is formed between the contact surfaces, helping to reduce friction and resist wear. With a tribometer featuring a pin-on-disk and fourball configuration, Guzman et al. [20] examined the impact of copper nanoparticle additives on the tribological properties of mineral and synthetic esterbased oils; they found that copper nanoparticles could improve the tribological properties of the mineral oil, although their effectiveness in synthetic polar oil was limited. Moreover, $\mathrm{Cu}$ nanoparticles exhibit good adaptability to the composition and hardness of diamond-like carbon (DLC) coatings. Zhang et al. [21] prepared $\mathrm{Cu}$ nanoparticles modified with diisooctyl dithiophosphoric acid (NPCuDDP); these were used as nano-additives in DLC/poly-alpha olefin (PAO) solid-liquid lubricating systems. They applied four types of DLC coatings with the hardnesses of 7-22 GPa, to investigate the tribological mechanism of NPCuDDP and its adaptability to the composition and hardness of DLC coatings. The results indicated that NPCuDDP could reduce the COF of DLC coatings and PAO systems by $19 \%-22 \%$, regardless of their composition and hardness; furthermore, they reduced the wear rate of all DLC coatings by 2-3 orders of magnitude. The superior friction reduction and anti-wear performances were attributed to the tribo-film formed on the friction surface, in turn attributable to the high activity of soft metal nanoparticles in NPCuDDP, as shown in Fig. 2.

However, the hydrophobicity of the diisooctyl dithiophosphoric acid (DDP) surface-capping layer makes it impracticable to use NPCuDDP in water-based lubricants. To address this, several researchers have sought to identify surface-capping agents that 

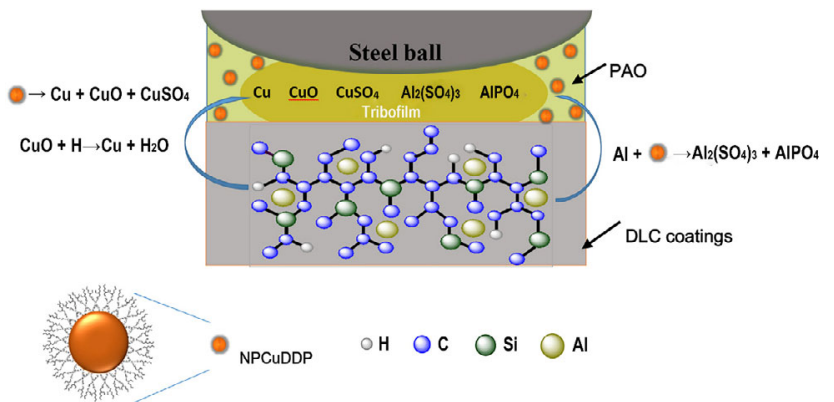

Fig. 2 Schematic diagram of friction mechanism of NPCuDDP in four DLC/PAO solid-liquid lubricating systems. Reproduced with permission from Ref. [21], (C) Elsevier 2019.

can effectively enhance the antioxidant capacity and dispersion stability of $\mathrm{Cu}$ nanoparticles in water-based lubricants. For example, Liu et al. [22] developed a water-in-oil reverse microemulsion method in which hydrophobic $\mathrm{Cu}$ nanoparticles were incorporated into silica spheres to prepare water-dispersible $\mathrm{Cu} @ \mathrm{SiO}_{2}$ nanoparticles. They also investigated the tribological properties of the prepared $\mathrm{Cu} @ \mathrm{SiO}_{2}$ nanoparticles when applied as a lubricant additive in distilled water. The results indicated that the prepared $\mathrm{Cu} @ \mathrm{SiO}_{2}$ nanoparticles offered sound antioxidant capacities and dispersion stability in distilled water and could considerably enhance the water's tribological properties.

\subsection{Nickel nanoparticles}

Beyond the traditional applications of soft metals, nickel nanoparticles have emerged as a novel type of additive for lubrication [23-26]. Using high-energy ion-beam evaporation technology and oleylamine, Zhao et al. [24] prepared surface-modified nickel nanoparticles to investigate the modification, frictionreduction, and anti-wear mechanisms as well as the tribological behaviors of lubricating oils with oleylamine-modified nickel nanoparticles. The results demonstrate that oleylamine-modified nickel nanoparticles are superior lubricant additives. Chen et al. [25] used dodecanethiol as a surface modification agent to synthesize $\mathrm{Cu}-\mathrm{Ni}$ bimetallic nanoparticles; they investigated and discussed the lubrication mechanism and tribological properties of surfacecapped $\mathrm{Cu}-\mathrm{Ni}$ bimetallic nanoparticles in liquid paraffin. The $\mathrm{Cu}-\mathrm{Ni}$ nanoparticles prepared with a sufficiently high concentration of dodecanethiol exhibited virtually no signs of aggregation and offered sound dispersibility in a variety of apolar solvents. It was also found that adding these nanoparticles could enhance the bearing capacity as well as the friction reduction and anti-wear performance of liquid paraffin. Using the pyrolysis of nickel formate, Zadoshenko et al. [26] prepared nickel nanoparticles with sizes varying from 12 to $34 \mathrm{~nm}$; these were added as lubricant additives to a low-temperature grease (CIATIM-201). Studies of the tribo-technical properties suggest that CIATIM-201 offers superiors anti-wear and extreme-pressure properties than pure grease when supplemented with nickel additives at concentrations of $0.05-0.2 \mathrm{wt} \%$ (Fig. 3).

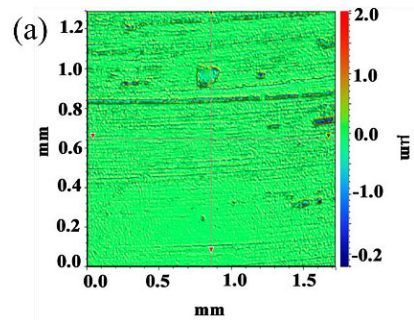

(d)

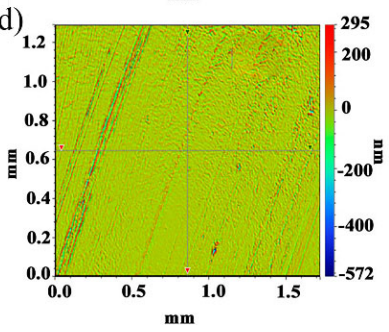

(b)

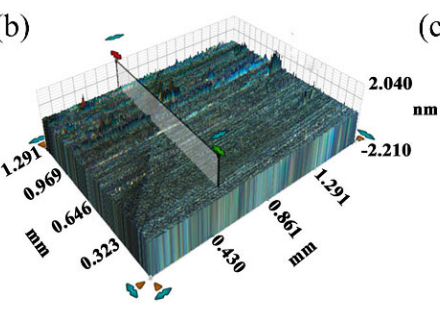

(e)

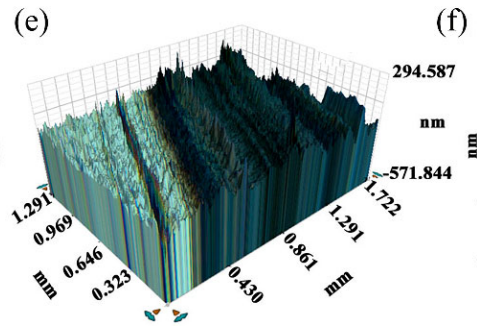

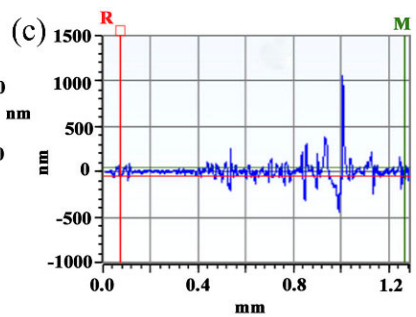

(f)

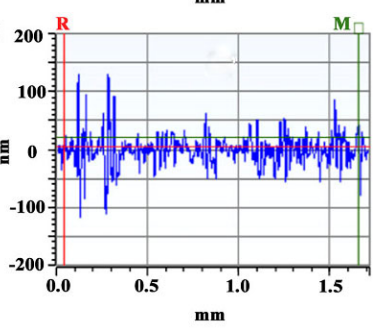

Fig. 3 (a-c) Optical microscopies of the friction surface in CIATIM-201 and (d-f) in CIATIM-201 + 0.2 wt\% nickel: $(a, d)$ two-dimensional surface images; (b, e) three-dimensional surface images; (c, f) roughness. Reproduced with permission from Ref. [26], (C) Taylor \& Francis 2020. 


\subsection{Molybdenum and tungsten}

Numerous studies have focused on the friction-reduction and anti-wear performances of soft metallic nanoadditives. However, it is unclear whether hard metallic nanoparticles make suitable lubricant additives. Zhang et al. [27] studied the extreme-pressure, frictionreduction, and anti-wear properties of two hard metallic nanoparticles ( $\mathrm{W}$ and $\mathrm{Mo}$ ) when added as lubricant additives to multialkylated cyclopentane (MAC) oil under vacuum, and they examined the tribological mechanisms of soft, medium-hard, and hard metallic nanoparticles as lubricant additives, as shown in Fig. 4. According to their results, the oil exhibited transient high friction under vacuum; this produced serious adhesive wear in the steel friction pairs, which could be efficiently eliminated with the $\mathrm{W}$ and Mo nano-additives. Specifically, both $\mathrm{W}$ and Mo nanoparticles optimally decreased the WSD and COF at a concentration of $0.5 \mathrm{wt} \%$. Moreover, because Mo nanoparticles can significantly impede the decomposition of the base oil and thereby extend its service life, Zhang et al. [27] considered them to be top-priority additives for MAC oil under vacuum conditions.

The lubrication mechanisms of metal nanoparticles include the followings [28]: (a) Tribo-films or adsorption films are generated, which alter the characteristics of the interface and segregate the two contact surfaces,

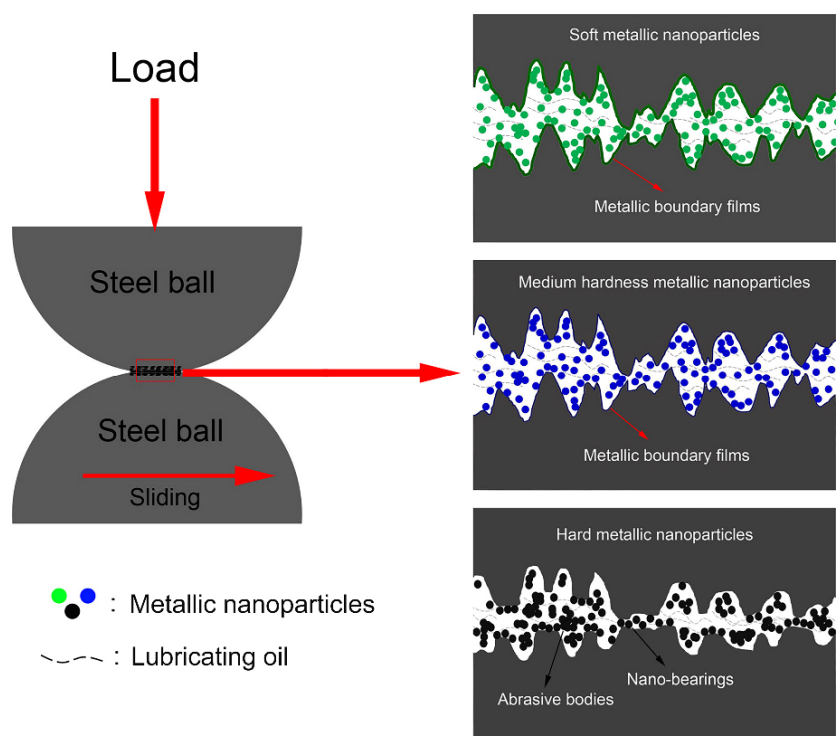

Fig. 4 Schematic of tribological mechanisms of metallic nanoparticle additives. Reproduced with permission from Ref. [27], (c) ASME 2017. thereby improving tribological performance; (b) the friction and wear are reduced through the rolling effect of nanoparticles between two sliding surfaces; (c) nanoparticles are compacted on the wear track by pressure and heat generated through the friction process; and (d) the nanoparticles can enter worn areas and repair worn surfaces through the small-size effect.

Nevertheless, metal nanoparticles with high chemical and surface activity levels are prone to agglomeration in practical applications and struggle to maintain long-term dispersion stability, which limits their applicability as lubricant additives. Hence, it is essential to enhance the chemical and dispersion stabilities of nanoparticles in lubricating oils. The surface modification method was most effective when metal nanoparticles were prepared to address the aforementioned problems; in this process, the surface energy was decreased to stabilize the metal nanoparticles and enhance their oil solubility $[16,24,25]$.

\section{Metal oxide nanoparticles}

Metal oxides are generally used individually or in combination as lubricant additives in base fluids, to reduce friction and wear. They exhibit lubrication mechanisms similar to those of metallic nanoparticles, including tribo-film or adsorption film formation, the rolling effect, and the repair or sintering effect. This section reviews two types of metal oxides: single and double.

\subsection{Single metal oxides}

A number of metal oxides (e.g., $\mathrm{CuO}, \mathrm{ZnO}, \mathrm{Fe}_{3} \mathrm{O}_{4}$, $\mathrm{TiO}_{2}, \mathrm{Co}_{3} \mathrm{O}_{4}$, and $\mathrm{Al}_{2} \mathrm{O}_{3}$ ) have been commonly used as lubricant additives [13, 29-32]. Several studies have investigated the use of $\mathrm{TiO}_{2}$ nanoparticles as lubricant additives [33, 34]. For example, a palm oil bio-lubricant containing $\mathrm{TiO}_{2}$ nano-additive was found to achieve its lowest $\mathrm{COF}$ and WSD when the concentration of the added nano-additive was $0.1 \mathrm{wt} \%$. Magnetic $\mathrm{Fe}_{3} \mathrm{O}_{4}$ nanoparticles (with an average particle diameter of $11.7 \mathrm{~nm}$ and solid weight fraction varying as $0-10 \mathrm{wt} \%$ ) were dispersed in alpha-olefin hydrocarbon synthetic lubricating oil [35]. The nanoparticles' COF reduction (45\%) and WSD reduction (30\%) performances were 
maximized at a concentration of $4 \mathrm{wt} \%$. The rolling effect was attributed to the reduced COF, and the reduced WSD was attributed to the spacer role played by magnetic nanoparticles among the asperities. Ali et al. [13] investigated the tribological behaviors of $\mathrm{Al}_{2} \mathrm{O}_{3}$ and $\mathrm{TiO}_{2}$ nanoparticles as lubricant additives in piston-ring assemblies. The results identified $45 \%$ and $50 \%$ frictional power reductions for the $\mathrm{Al}_{2} \mathrm{O}_{3}$ and $\mathrm{TiO}_{2}$ nano-lubricants, respectively; this was attributed to the rolling friction effect and the tribo-films formed on the worn surfaces. Notably, the $\mathrm{Al}_{2} \mathrm{O}_{3}$ nanolubricant better enhanced the scuffing resistance and anti-wear performance because of the formation of self-laminating protective films, and the $\mathrm{TiO}_{2}$ nanolubricant was more efficient in reducing the $\mathrm{COF}$ because of its rolling effect. Hernández et al. [31] investigated the anti-wear behavior of $\mathrm{CuO}, \mathrm{ZnO}$, and $\mathrm{ZrO}_{2}$ nanoparticle suspensions in PAO6 under mixed lubrication conditions, using a block-on-ring tribometer. The results demonstrated that all nanoparticle suspensions offered improved friction-reduction and anti-wear performances compared to the base oil. Moreover, as opposed to $\mathrm{CuO}, \mathrm{ZrO}_{2}$ and $\mathrm{ZnO}$ suspensions offered tribological performances that improved as a function of nanoparticle content. It was concluded that the tribo-sintering of nanoparticles on the worn surface prevented metal-to-metal contact and produced load-bearing areas. Bhaumik et al. [36] examined the tribological performance of $\mathrm{ZnO}$ nanofriction-modifier-based castor oil between steel surfaces for various concentrations. The results showed that neat castor oil supplemented with $0.1 \mathrm{wt} \% \mathrm{ZnO}$ achieved the lowest wear rate, and a larger concentration of $\mathrm{ZnO}$ produced a higher one. The diffusion of zinc oxide nanofriction modifiers and the adsorption of castor oil in the surface grooves produced a tribo-film. This prevented intermetallic contact, thereby reducing the COF and surface roughness. However, $\mathrm{ZnO}$ nanofriction modifiers induce deterioration of the mating surfaces at high concentrations, as shown in Fig. 5.

\subsection{Double metal oxides}

With a higher thermal stability and lower Mohs hardness than individual oxides, double metal oxides have been applied to protect contacting surfaces at elevated temperatures. Typically, they are prepared either directly or by tribo-chemical reactions during friction [37]. Because of their high ductility and shear susceptibility at elevated temperatures, double metal oxides have been extensively studied as a possible solid lubricant material or lubricant additive [38, 39]. Ye et al. [40] prepared nickel oxythiomolybdate $\left(\mathrm{NiMoO}_{2} \mathrm{~S}_{2}\right)$ nanoparticles with an average size of $13 \mathrm{~nm}$ and assessed the tribological properties of these nanoparticles as a lubricant additive at high temperatures, using a four-ball-wear and a pin-on-disc tester. In their results, the $\mathrm{NiMoO}_{2} \mathrm{~S}_{2}$ nanoparticles demonstrated excellent anti-friction capabilities when used as an additive in liquid lubricants at room temperature of $20{ }^{\circ} \mathrm{C}$ or in solid lubricants at high temperatures. A series of studies on the application of perrhenate as additives for lubrication at high temperatures or across an extensive range of temperatures were conducted by Wang et al. [41-44]. The prepared silver perrhenate powders were added to

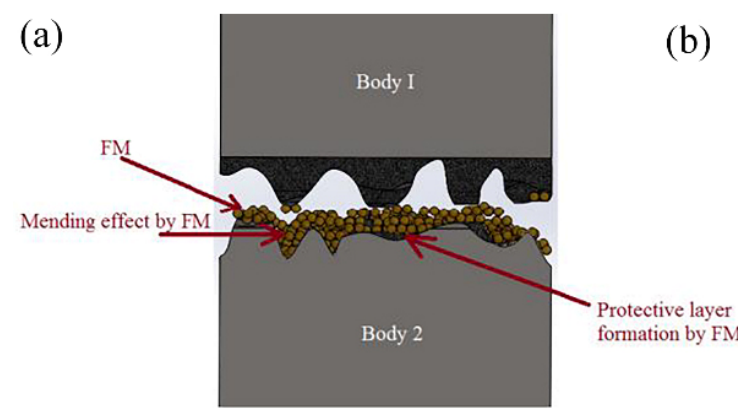

(b)

(c)

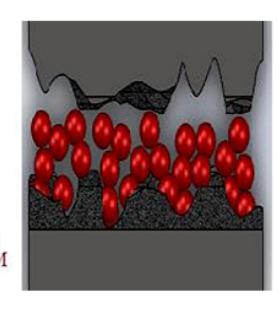

(d)

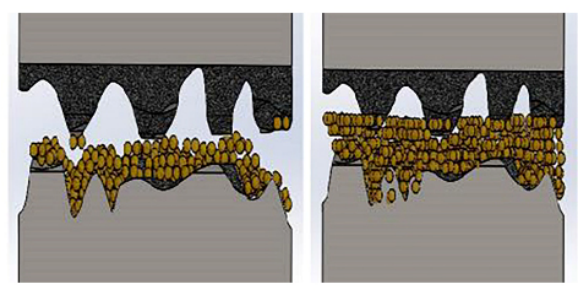

Fig. 5 Schematic diagram of (a) the lubrication mechanism, (b) the neat castor oil containing graphite between the sliding bodies, (c) neat castor oil containing the optimal concentration of nano friction modifiers between the sliding bodies, and (d) neat castor oil containing higher concentration of nano friction modifiers (FMs) leading to blockage of oil and agglomeration of friction modifiers. Reproduced with permission from Ref. [36], C Elsevier 2018. 
PAO base oil containing polyoxyethylene octylphenyl ether [42]. The results indicated that when silver perrhenate was added, the oil exhibited superior friction-reduction and anti-wear characteristics to the base oil. An optimal performance was achieved at a concentration of $0.5 \mathrm{wt} \%$. This excellent lubrication performance was attributed to the barrier function performed by the silver perrhenate layer, which incorporated native superalloy oxides generated on the worn surface and thereby prevented direct contact between the friction surfaces at high temperatures.

\section{Carbon nanomaterials}

Recently, carbon nanomaterials (of 0-3 dimensions) have been applied as lubricant additives in base fluids to improve tribological performance. Different forms of carbon nanomaterials operate by different lubrication mechanisms. Therefore, this section introduces carbon nanomaterials in four sections: zero-, one-, two-, and three-dimensional.

\subsection{Zero-dimensional carbon nanomaterials}

\subsubsection{Fullerene}

$\mathrm{Ku}$ et al. [45] assessed the anti-wear and extreme pressure properties of fullerenes with different viscosities, using a disk-on-disk mode. Adding fullerene nanoparticles primarily reduced friction by minimizing the contact between the metal surfaces. Furthermore, fullerene achieved a superior performance when it was added to oils with lower viscosities. Kalin et al. [46] examined the effectiveness of fullerene nanoparticles added to 20W50 base oil, comparing their effectiveness against those of other carbon nanomaterials. A planetary ball milling method was used to disperse the nanoparticles in oil. Because no precipitation was observed after 30 days, the stability of fullerene nanoparticles in oil was deemed acceptable. Fullerene was also shown to produce a lower thermal conductivity increase than all other carbon nanomaterials.

\subsubsection{Carbon quantum dots (CQDs)}

As an emerging class of carbon-based nanoparticles, CQDs and their derivatives have extremely small sizes and distinctive properties, and numerous studies have explored their lubrication characteristics. Because of their oxygen-containing groups and easy preparation procedures, CQDs exhibit ideal friction-reduction and anti-wear properties when used as a lubricant additive [47]. Because their surfaces are filled with hydroxyl and carboxyl groups, CQDs are often used as functional components for constructing new nanostructured materials, in which their graphitic structures and small sizes realize excellent lubrication properties [48]. Ma et al. [49] fabricated ionic-liquidmodified CQDs as lubricant additives and managed to achieve superlubricity. Xiao et al. [50] fabricated water-soluble CQDs and added them as lubricant additives to deionized water. They experimentally observed the tribological behaviors of the CQDs in deionized water for both $\mathrm{Si}_{3} \mathrm{~N}_{4} / \mathrm{Si}_{3} \mathrm{~N}_{4}$ and $\mathrm{Si}_{3} \mathrm{~N}_{4} /$ steel contacts. The results showed that adding CQDs could reduce the COF in both types of friction pairs. The maximal COF reduction was $14 \%$ and $30 \%$ for the $\mathrm{Si}_{3} \mathrm{~N}_{4} / \mathrm{Si}_{3} \mathrm{~N}_{4}$ and $\mathrm{Si}_{3} \mathrm{~N}_{4} /$ steel contacts, respectively. Wang et al. [51] investigated the tribological performance of ionic liquid (IL)-capped CDs when used as lubricant additives for PEG, by altering the additive concentration, the duration, and test load. These additives were found to exhibit excellent frictionreduction and anti-wear properties. More specifically, a PEG base stock supplemented with $0.3 \mathrm{wt} \%$ of additive under a test load of $392 \mathrm{~N}$ could decrease the COF and WSD of the lower balls by $70 \%$ and $33 \%$, respectively. Ye et al. [47, 52] studied multifunctional CQDs (referred to as CQDs-N) as lubricant additives in a polar base fluid of biobased castor oil. They also produced liquid-like CQDs- $\mathrm{N}$ with oleylamine capped on the surface (referred to as O-CQDs-N), by using a chemical grafting route. Both the CQDs-N and O-CQDs-N exhibited excellent dispersion stability in castor oil and PAO, improving both the anti-wear and anti-oxidant performances of these substances. They also generated 3D images and height profiles (represented as red lines) of the wear scars achieved after lubrication by PAO alone and PAO with $0.5 \mathrm{wt} \%$ O-CQDs-N; these are presented in Fig. 6. It was speculated that the thin protective film formed by the CQD-based nanoparticles deposited on the worn surface could improve the lubrication performance as well as the loading capacity of the lubricant, as shown in Fig. 7. 

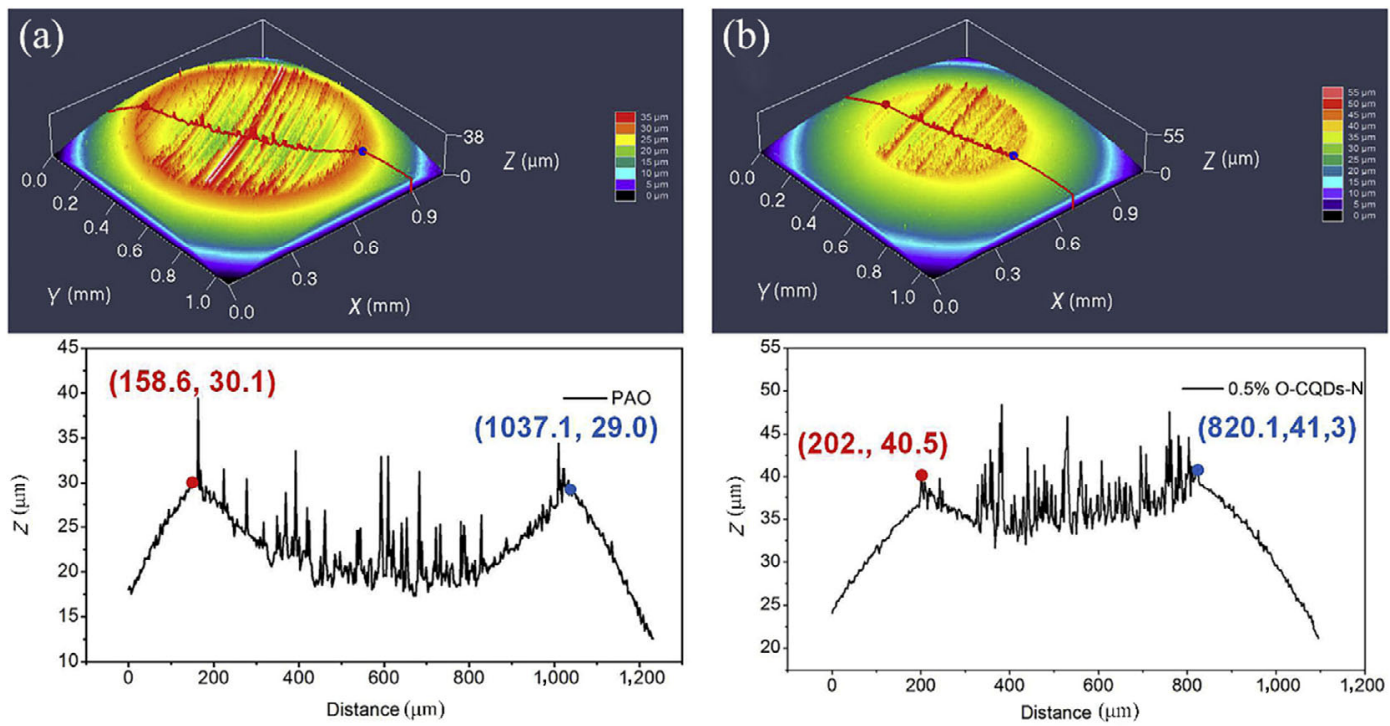

Fig. $63 \mathrm{D}$ images and the corresponding height profiles (red lines) of the wear scar lubricated by (a) PAO and (b) $0.5 \mathrm{wt} \% \mathrm{O}-\mathrm{CQDs}-\mathrm{N}$ in PAO, respectively. Reproduced with permission from Ref. [47], C Elsevier 2019.

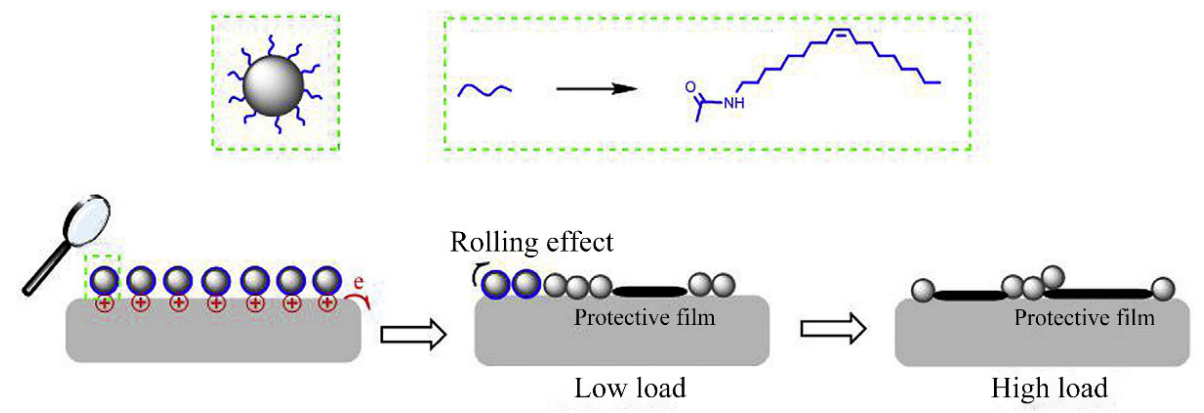

Fig. 7 Proposed tribological mechanism of O-CQDs-N. Reproduced with permission from Ref. [47], (C) Elsevier 2019.

\subsection{One-dimensional carbon nanomaterials}

Typical one-dimensional nanomaterials include nanotubes, nanowires, and nanorods; these are widely used in industrial applications. Carbon nanotubes (CNTs) are one of the most extensively investigated classes of carbon nanomaterials [53, 54]. A CNT is a tubular structure composed of hexagonal rings of carbon atoms. Such tubes can be up to several millimeters in length and several nanometers in diameter [55]. Owing to their outstanding thermal and mechanical properties and their self-lubricating effect, CNTs have been extensively applied in tribological tasks as water or oil-based lubricant additives, or as reinforcements for metals or polymers [53, 56]. Adding $1.0 \mathrm{wt} \%$ of multiwalled carbon nanotubes (MWCNTs) as an additive in Mobilgear 627 and paraffinic mineral oils was found to improve the anti-wear performances and load-carrying capacities of the base lubricants [57].
The analysis results show that adding MWCNT nanoparticles to the base oil reduces wear and produces a smoother surface with fewer scars, further confirming that the addition of MWCNTs can effectively reduce direct metal-to-metal contacts. The MWCNT nanoparticles deposited on the worn surface reduce the shearing stress, thereby enhancing the tribological performance [58]. Gong et al. [59] found that when added as an additive to polyalkylene glycol-based oil, the CNTs could significantly improve the oil's friction-reduction and anti-wear capabilities, by forming boundary lubrication films. Moreover, the tribological properties of water can also be enhanced by the transferal of an amorphous carbon film from the CNTs [60]. Peng et al. [61] investigated the tribological behavior of functionalized MWCNTs added to water. The results show that the presence of MWCNTs can enhance the load-carrying capacities of the base fluid and decrease the COF and WSD. 
Rolling is crucial to the lubrication mechanism of CNT additives in liquid lubricants. This suggests that CNTs tend to roll between two sliding surfaces [53, 62]. Hence, the diameters and lengths of CNTs can profoundly affect their ability to enter the clearance of the friction pair, thereby reducing friction and wear. Several experiments have been performed to identify the diameter and length at which CNTs perform best as a lubricant additive. For example, Ye et al. [56] experimentally examined the tribological properties of several CNTs of varying diameters and lengths when added to water and liquid paraffin. It was revealed that short CNT samples outperformed longer ones. In addition, the middle-diameter (10-20 nm) ones were found to deliver the strongest anti-wear performance in both lubricants, as shown in Fig. 8.

However, CNTs tend to wrap and form conglomerates. This results in a robust electrostatic and van der Waals force between molecules or atoms on the surface. This force generates large aggregations, leading to incomplete oil films and large winding accumulations at the interface [54]. In these cases, the CNTs cannot achieve a rolling or "micro-bearing" effect comparable to that of other spherical nanoparticles; hence, their friction-reducing capabilities are limited. To facilitate the stable uniform dispersion of CNTs and prevent them from winding and conglomerating, numerous experiments have been
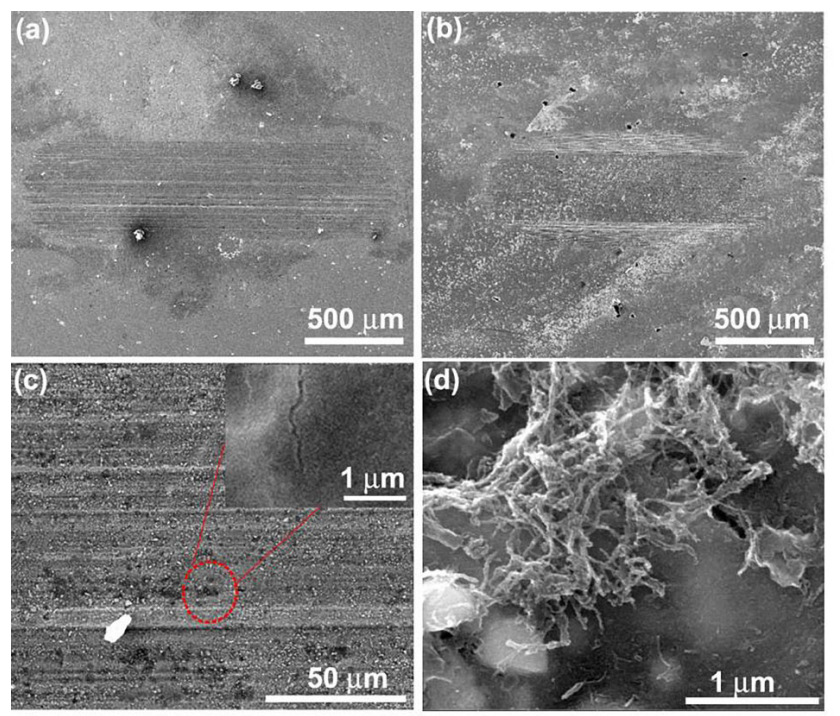

Fig. 8 (a) Low and (c) high magnification worn surfaces by the water lubrication, and (b) low and (d) high magnification worn surfaces by the OMWCNTs- 5 as lubricant additive in water. Reproduced with permission from Ref. [56], (c) Elsiver 2019. conducted to study the dispersing effects of different surfactants on CNTs. Based on molecular mechanics simulations designed from an energy perspective, Duan et al. [63] investigated the dispersion of CNTs with sodium dodecyl sulfate.

Another approach to address the problem of MWCNTs is to develop novel carbon nanomaterials such as partially exfoliated multiwalled carbon nanotubes (Px-CNTs) [64]. Px-CNTs are carbon nanotubes partially wrapped by nanoribbons, similar to long-shaped graphene oxide (GO) sheets. As a combination of MWCNTs and graphene, Px-CNTs offer superior capacitance to the former, owing to the enhanced defect density and effective surface area of the exfoliated tubular structures. Unlike pure MWCNTs, Px-CNTs have a long nanotube structure that prevents the coalescence of bands. Simultaneously, the inner walls of the Px-CNTs remain as intact as those of the MWCNTs, with the external tubes exfoliated into nanoribbons to reduce entanglement. Sun et al. [64] fabricated Px-CNTs by oxidizing multiwalled carbon nanotubes; these were used as lubrication additives in water-based fluids, and an excellent friction reduction was achieved. A physical tribo-film formed by Px-CNT dispersion between interfaces prevented direct contact between the friction surfaces; this could be observed from the structure and friction testing of Px-CNTs. Moreover, the Px-CNTs were deposited in the grooves of the surfaces and adsorbed on the friction surfaces, whilst the layer nanosheets ensured sliding susceptibility and the tubes functioned as rolling bearings, as shown in Fig. 9.

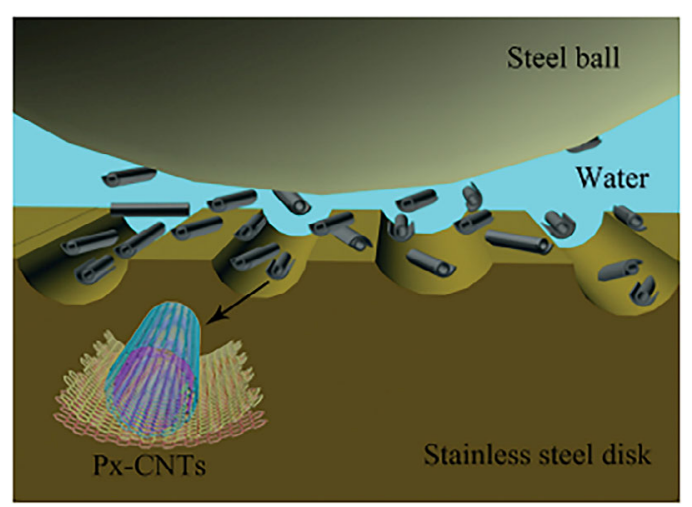

Fig. 9 Mechanism of water-based lubricant with Px-CNTs presents the synergetic effect of the parts of nanotubes and nanoribbons. Inset: the schematic diagram of Px-CNTs. Reproduced with permission from Ref. [64], (C) American Scientific Publishers 2018. 


\subsection{Two-dimensional carbon nanomaterials: graphene and GO}

Graphene has gained extensive research attention owing to its distinctive structure and excellent mechanical, optical, electrical, and thermal properties. In particular, graphene has been recognized as an ideal candidate for both solid lubricants and lubricant additives, owing to its outstanding mechanical strength, high thermal and chemical stability, low shear strength, atomically smooth surface, excellent specific surface area, and ultra-low film thickness [65-69].

A number of studies have investigated the tribological performance and lubrication mechanisms of graphene applied as an additive in lubricants. Using a UMT-2 friction and wear testing machine, Zhao et al. [70] examined the abrasive resistance of graphene, and the results demonstrated that the graphene significantly improved the friction-reduction and anti-wear performance. More specifically, the maximum COF and wear rate were reduced by $78 \%$ (Fig. 10) and 95\%, respectively. Senatore et al. [71] investigated the tribological performance of GO nanosheets in mineral oil. The experimental results show that, at temperatures ranging from 25 to $80{ }^{\circ} \mathrm{C}$, the average $\mathrm{COF}$ was reduced by $\sim 20 \%$, and the anti-wear rate was reduced by $\sim 30 \%$. Graphene and GO have similar frictionreduction mechanisms; that is, they both form a protective film to separate the two contact surfaces [71]. Mao et al. [72] performed a comparative study to investigate the tribological performance of graphene when applied as a lubricant additive for steel/steel and steel/copper friction pairs. According to their results, graphene achieved superior lubrication in

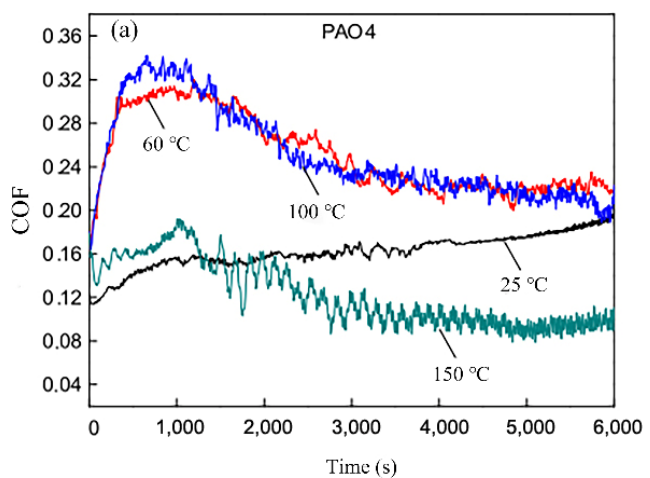

steel/steel friction pairs than steel/copper ones. This was because the steel/copper friction pairs were subjected to serious plastic deformation on the surface of the copper, which decreased the stability of the graphene tribo-film.

Despite its ability to reduce friction and resist wear, graphene tends to agglomerate in the base lubricating oil; this significantly degrades its lubrication performance. Therefore, graphene must maintain dispersion stability when used as a lubricant additive in different base lubricants. One of the most efficient approaches to improve the dispersion stability of graphene is to regulate its physical form. Li et al. [73] fabricated highly exfoliated reduced GO via thermal reduction and increased the specific surface area of graphene, as shown in Fig. 11. They also obtained a stable dispersion time of 4 days for this graphene in PAO6. After adding $0.5 \mathrm{wt} \%$ reduced GO to PAO6, decreases of $44 \%$ and $90 \%$ were achieved in the COF and the wear-track depth, respectively. Dou et al. [74] studied how crumpled graphene balls could be effectively applied as lubricant additives in PAO4; the crumpled balls offered improved dispersion stability in the base oil compared to graphite and commercially available reduced graphite oxide. It was also speculated that graphene balls could have a ball-bearing effect during friction, thereby enhancing the friction-reduction and anti-wear performance of PAO4.

Chemical modification represents another approach for improving the dispersibility of graphene [75]. To enhance graphene's dispersion stability in water, an oxygen-containing functional group was grafted onto graphene sheets via oxidation. Kinoshita et al. [76]

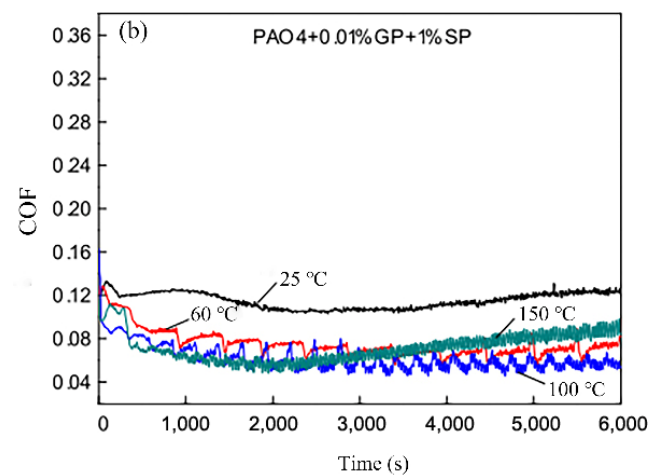

Fig. 10 Variations of the COF with sliding time at different temperatures: (a) PAO4 and (b) PAO4 $+0.01 \%$ Graphene $+1 \%$ Span- 80 . Reproduced with permission from Ref. [70], (c) Acta Metallurgica Sinica 2017. 


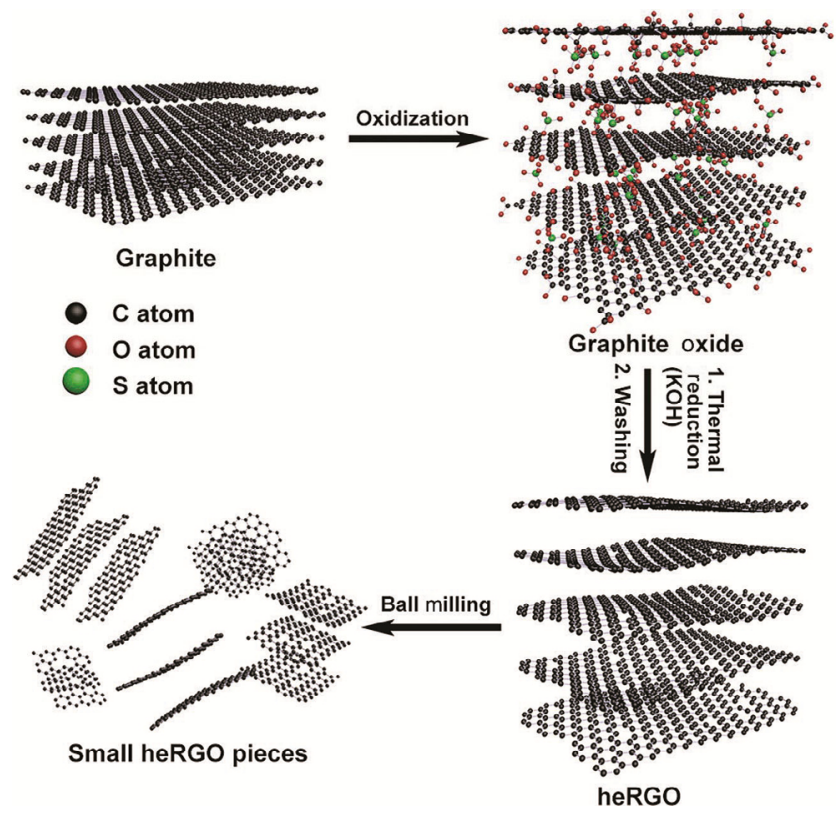

Fig. 11 Schematic illustration of the preparation of heRGO-n powders. Reproduced with permission from Ref. [73], C WILEYVCH Verlag GmbH \& Co. KGaA, Weinheim 2016.

studied the lubrication properties of GO when added to pure water. A COF of $\sim 0.05$ was obtained by GO dispersion; this was lower than the values obtained under lubrication with pure water $(\mathrm{COF}>0.4)$ and water-based emulsion lubricants (COF $\approx 0.12$ ). Furthermore, no evident surface wear was observed, even after 60,000 cycles of friction testing. The experimental results suggest that the GO sheets adsorbed onto the ball and flat plate during sliding may function as protective coatings on both solid surfaces. Using stearic and oleic acids as raw materials, Lin et al. [77] grafted alkylene chains onto graphene sheets using a cyclic heating method, thereby improving the dispersion stability of graphene in base oil. After $200 \mathrm{~min}$, they found that the unmodified graphene had largely agglomerated in the base oil; however, for the modified graphene, little precipitation was observed. When $0.075 \mathrm{wt} \%$ modified graphene was added, the base oil exhibited a COF of $\sim 0.12,33.3 \%$ lower than that of pure base oil.

The use of dispersants is another effective method for enhancing the dispersion stability of graphene in base oils. Cai et al. [78] used Span-80 $\left(\mathrm{C}_{24} \mathrm{H}_{44} \mathrm{O}_{6}\right)$ as a dispersant, to improve the dispersion stability of graphene in PAO4. Three days later, the PAO4 supplemented with $0.05 \mathrm{wt} \%$ graphene and $1 \mathrm{wt} \%$
Span-80 was darker and more turbid than when $0.05 \mathrm{wt} \%$ graphene was added. This suggests that Span-80 was effective in improving the dispersion stability of graphene in the base oil. Wu et al. [75] developed a dispersing method in which graphene was chemically modified by octadecylamine and dicyclohexylcarbodiimide and combined with an efficient dispersant to provide excellent dispersion stability in the base oil. The graphene (0.5 wt\%) modified with dispersant (1 wt\%) maintained a stable dispersion in PAO6 for up to 120 days. It was reported to obtain a COF of $\sim 0.10$ between sliding surfaces and a $\sim 21 \mathrm{~nm}$ wear-track depth on the plate, $\sim 44 \%$ and $90 \%$ lower than the results obtained for pure PAO6, respectively.

Graphene or GO with its unique two-dimensional lattice structure, outstanding mechanical performance, and stable physicochemical characteristics, is being increasingly applied in lubrication applications. Varying the preparation, functional modification, and physical composition of graphene is a feasible method of achieving excellent tribological properties and extending the applicability of these materials in the field of tribology. Current tribological studies on graphene have promoted the use of graphene in tribological applications and for reducing energy loss. However, doubts and difficulties remain regarding the structure and shape of graphene, the optimal additive quantities, and the specific action mechanisms. In addition, factors such as the preparation, modification procedures, and the type of dispersant to be added also affect the tribological performance of graphene to varying degrees. Therefore, to improve graphene's applicability as a lubricant in tribological applications, it is necessary to further examine the tribological mechanism of graphene as well as the structural changes and interactions of the lubricating system under friction conditions.

\subsection{Three-dimensional carbon nanoparticles}

\subsubsection{Graphite}

Graphite can be used both as a powder lubricant and a powder additive [79-81]. Hwang et al. [79] investigated how the size and shape of nanoparticles containing graphite could affect the tribological 
performance. Adding graphite helps to reduce wear and scar formation on sliding surfaces; this is mostly attributable to its role as a ball bearing between friction surfaces. Lee et al. [80] investigated how graphite could be used as a lubricant additive in industrial gear oil. The results indicate that adding graphite nanoparticles to a lubricant can enhance its lubrication properties. The nanoparticles present between the friction interfaces reduce the direct contact between plates, by functioning as ball bearings. Morphological analysis (Fig. 12) suggests that adding graphite nanoparticles into base fluids can reduce wear and produce a smoother surface with fewer scars, further demonstrating the ability of graphite nanoparticles to minimize direct metal-to-metal contact.

\subsubsection{Diamond}

Nano-sized diamond particles have been proven capable of functioning as ball bearings between sliding parts in a machine [82]. Chu et al. [83] examined the tribological performance of a lubricating oil supplemented with nano-diamond additives at various volumetric concentrations. According to their experimental results, the presence of nano-diamond (ND) particles enhanced the anti-scuffing capability of the base stock. By adding ND particles to the oil samples, the number of scuffing-induced surface failures could be reduced. More specifically, the friction

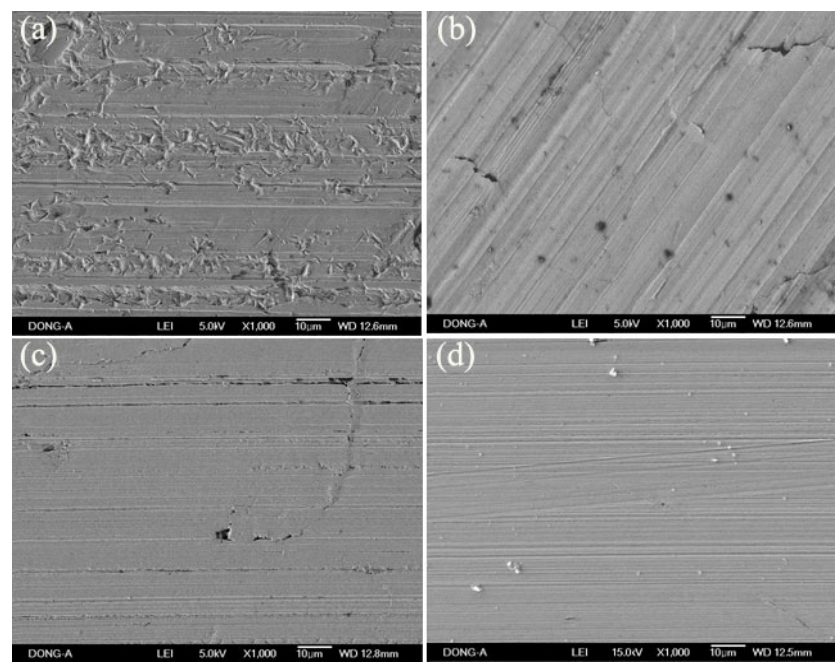

Fig. 12 SEM images of the worn surfaces tested using lubricants that containing graphite nanoparticles: (a) surface before test, (b) raw lubricant, (c) 0.1 vol\% nano lubricant, and (d) 0.5 vol\% nano lubricant. Reproduced with permission from Ref. [80], (C) Springer Nature 2009. was largely reduced after a $2 \%$ or $3 \%$ addition of ND particles to the base oil.

\section{Other nanomaterials}

Alongside the aforementioned materials, several typical or emerging materials are widely used in the field of lubrication additives, including metal sulfides, hexagonal boron nitride, and black phosphorus. Considering the structure of the present article, we classify these materials as "other" nanomaterials.

\subsection{Metal sulfides}

Recently, layered-structure materials such as $\mathrm{WS}_{2}$ and $\mathrm{MoS}_{2}$ have become popular as lubricant additives in base fluids, owing to their high shear susceptibility. Studies on transition metal disulfide liquid additives $\left(\mathrm{MoS}_{2}\right.$ in particular) have primarily focused on the fabrication of functional $\mathrm{MoS}_{2}$ nanosheets [84, 85], $\mathrm{MoS}_{2}$ nanotubes [86, 87], hollow fullerene-like $\mathrm{MoS}_{2}$ [88], $\mathrm{Fe}_{3} \mathrm{O}_{4} @ \mathrm{MoS}_{2}$ core-shell nanocomposites [89], and $\mathrm{MoS}_{2} /$ montmorillonite nanocomposites [90]. Yi and Zhang [91] fabricated three different types of morphological $\mathrm{MoS}_{2}$ particles using hydrothermal and solvothermal methods. The addition of these $\mathrm{MoS}_{2}$ particles enhanced the tribological performance of liquid paraffin, and the enhancement was most significant after the addition of $\mathrm{MoS}_{2}$ nanosheets. $\mathrm{Hu}$ et al. [92] compared the tribological performances obtained by using $\mathrm{WS}_{2}$ with different morphologies as lubricant additives under various load conditions. The friction-reduction and anti-wear mechanisms of the different forms of $\mathrm{WS}_{2}$ during the tribological process are shown in Fig. 13. (a)

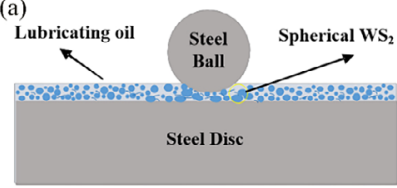

(c)

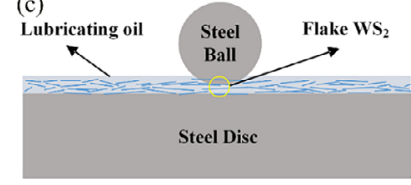

(b)

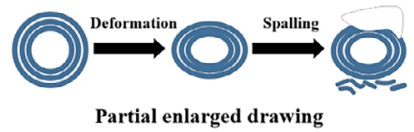

(d)

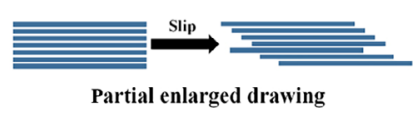

Fig. 13 (a, b) Lubrication mechanism of spherical and (c, d) flaky $\mathrm{WS}_{2}$ as lubricating oil additive. (a, c) Overall schematic and (b, d) schematic details. Reproduced with permission from Ref. [92], (C) MDPI 2020. 
Extensive studies have been performed on the use of $\mathrm{MoS}_{2}$ and $\mathrm{WS}_{2}$ nanoparticles as effective oil additives, because of their ideal thermal and chemical stability, nanometric sizes, outstanding lubricant properties, and other advantages. Despite their excellent tribological performance, $\mathrm{MoS}_{2}$ nanosheets still struggle to form stable dispersions in fluids. Numerous studies have sought to improve the dispersion stability of $\mathrm{MoS}_{2}$ in base fluids, primarily through functionalization and modification [84, 93-95]. More specifically, the small size, large surface area, and quantum size effects of $\mathrm{MoS}_{2} / \mathrm{WS}_{2}$ QDs could play a pivotal role in the formation of stable dispersions in PAG base oil supplemented with solid nanoparticles. These impressive physical properties have motivated scholars to examine the applicability of $\mathrm{WS}_{2}$ and $\mathrm{MoS}_{2}$ QD additives [96]. Gong et al. [97] prepared $\mathrm{MoS}_{2}$ and $\mathrm{WS}_{2}$ QDs and dispersed them in 1-butyl-3-methylimidazolium hexafluorophosphate to obtain homogeneous dispersions with long-term stability. According to the tribological results, adding $\mathrm{WS}_{2}$ and $\mathrm{MoS}_{2}$ QDs to this IL significantly enhanced the friction-reduction and antiwear performance of the base fluid. This enhancement was attributed to protective films generated through the physical absorption of additives and the tribochemical reaction between $\mathrm{WS}_{2} / \mathrm{MoS}_{2}$ and the iron oxides/atoms.

\subsection{Rare-earth compounds}

Because of their distinctive physical and chemical characteristics, rare-earth elements have attracted extensive attention from the tribology research community. The most-investigated rare-earth compounds are lanthanum and cerium compounds; these can be applied as lubricant additives either individually or in combination with other nanoparticles such as $\mathrm{TiO}_{2}$ [28]. The friction-reduction and anti-wear mechanisms of these compounds can be explained by the generation of a tribo-film or adsorption film on the contact interface. In addition, several studies have been conducted to explore the tribological behaviors of rare-earth compound (e.g., $\mathrm{CeVO}_{4}, \mathrm{Y}_{2} \mathrm{O}_{3}, \mathrm{La}(\mathrm{OH})_{3}$, and $\mathrm{LaF}_{3}$ nanoparticles) additions to base fluids [98-100]. Zhao et al. [101] discovered that the La element in nano- $\mathrm{La}(\mathrm{OH})_{3}$ could serve as a catalyst to accelerate the ion-exchange reaction of $\mathrm{O}, \mathrm{Si}$, and $\mathrm{Fe}$ tribo-film formation, thereby improving the tribological properties of serpentine/ $\mathrm{La}(\mathrm{OH})_{3}$ composites compared to the single serpentine or $\mathrm{La}(\mathrm{OH})_{3}$ particle when added to lubricating oils. A mixture of cerium oxide ( $\approx 90 \mathrm{~nm}$ ) and paraffin oil (as a nano-lubricant) has also been investigated [6]. Rare-earth compounds can dramatically extend the working life of lubricating oils, whilst allowing for a 2-4 fold increase in the anti-wear capacities of machines and a 10\%-100\% increase in the load-carrying capacity of the lubricating oils. Moreover, rare-earth compounds have been found to offer superior lubrication performance when combined with other additives [28].

\subsection{Layered double hydroxides (LDHs)}

Wang et al. [102] fabricated three types of nanosized $\mathrm{Ni}-\mathrm{Al}$ layered double hydroxides (LDHs), by adjusting the hydrothermal reaction time during microemulsification. Transmission electron microscopy and atomic-force microscopy were used to demonstrate the samples' layered structures and 3D nanoscale architectures. The samples were added as lubricant additives to a gas-to-liquid 8 (GTL8) base oil, and a ball-on-disk tribometer was used to evaluate the tribological performance of the samples under different loads. After adding nano-LDH at a contact pressure of $2.16 \mathrm{GPa}$, the COF was reduced by $\sim 10 \%$, and the anti-wear performance was improved. As shown in Fig. 14, the larger nanoplatelets (NiAl-24 h) (as opposed to the smaller ones (NiAl-6 h)) exhibited outstanding tribological properties, attributable to their superior crystallinity and the formation of a tribo-film with unique mechanical properties under friction conditions. Hence, nano-LDHs offer excellent tribological performances and hold significant potential as lubricant additives for industrial applications.

Wang et al. [103] fabricated NiAl-LDH nanoplatelets with a few ordered layers, using a microemulsion method. As shown in Fig. 15(a), the nanoplatelets stabilized because electrostatic interactions occurred between the polarized $\mathrm{OH}^{-}$groups of NiAl-LDH and the $-\mathrm{NH}^{+}$head groups of oleylamine; furthermore, the hydrophobicity of the nanoplatelets was reduced by the $-\mathrm{OH}$ groups of the assistant surfactant 1-butanol. After directly dispersing the nanoplatelets in water, a stable translucent solution was obtained. 

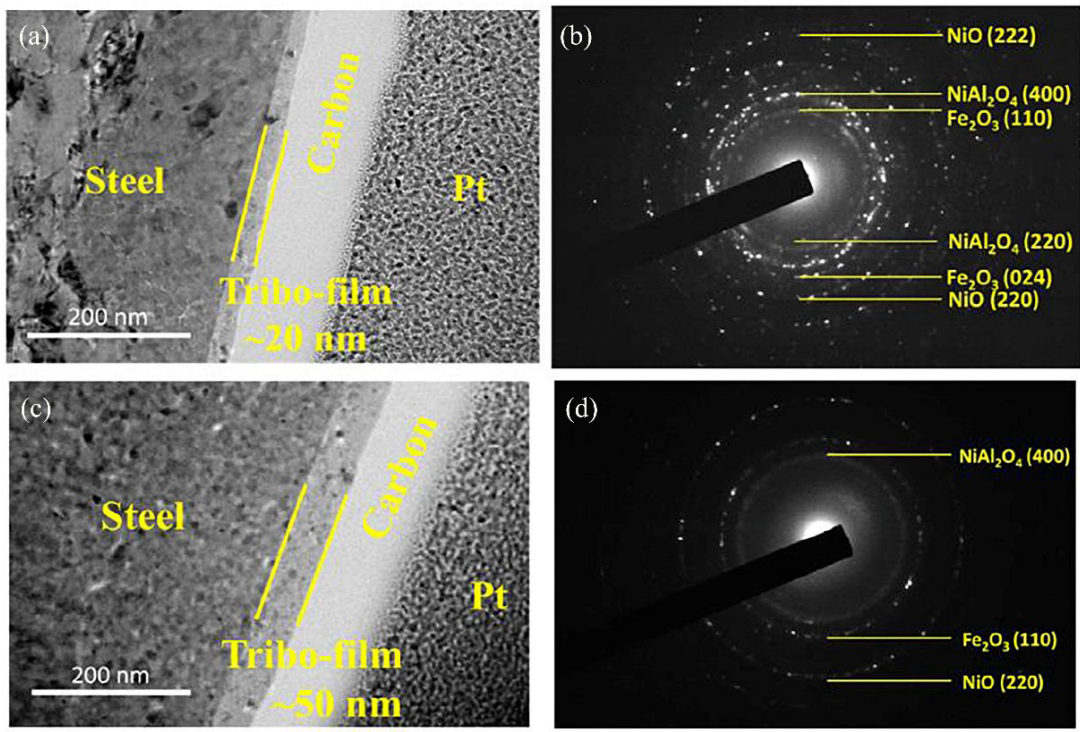

Fig. 14 Analysis of tribofilm formed on the wear track lubricated by $(\mathrm{a}, \mathrm{b}) 1 \mathrm{wt} \% \mathrm{Ni}-\mathrm{Al} \mathrm{LDHs}$ with a hydrothermal reaction time of $24 \mathrm{~h}$ (NiAl-24 h) and (c, d) $1 \mathrm{wt} \% \mathrm{Ni}-\mathrm{Al}$ LDHs with a hydrothermal reaction time of $6 \mathrm{~h}$ (NiAl-6 h) at $100 \mathrm{~N}$. (a, c) Cross-sectional TEM images and (b, d) diffraction patterns of tribofilm. Reproduced with permission from Ref. [102], (C) American Chemical Society 2017.
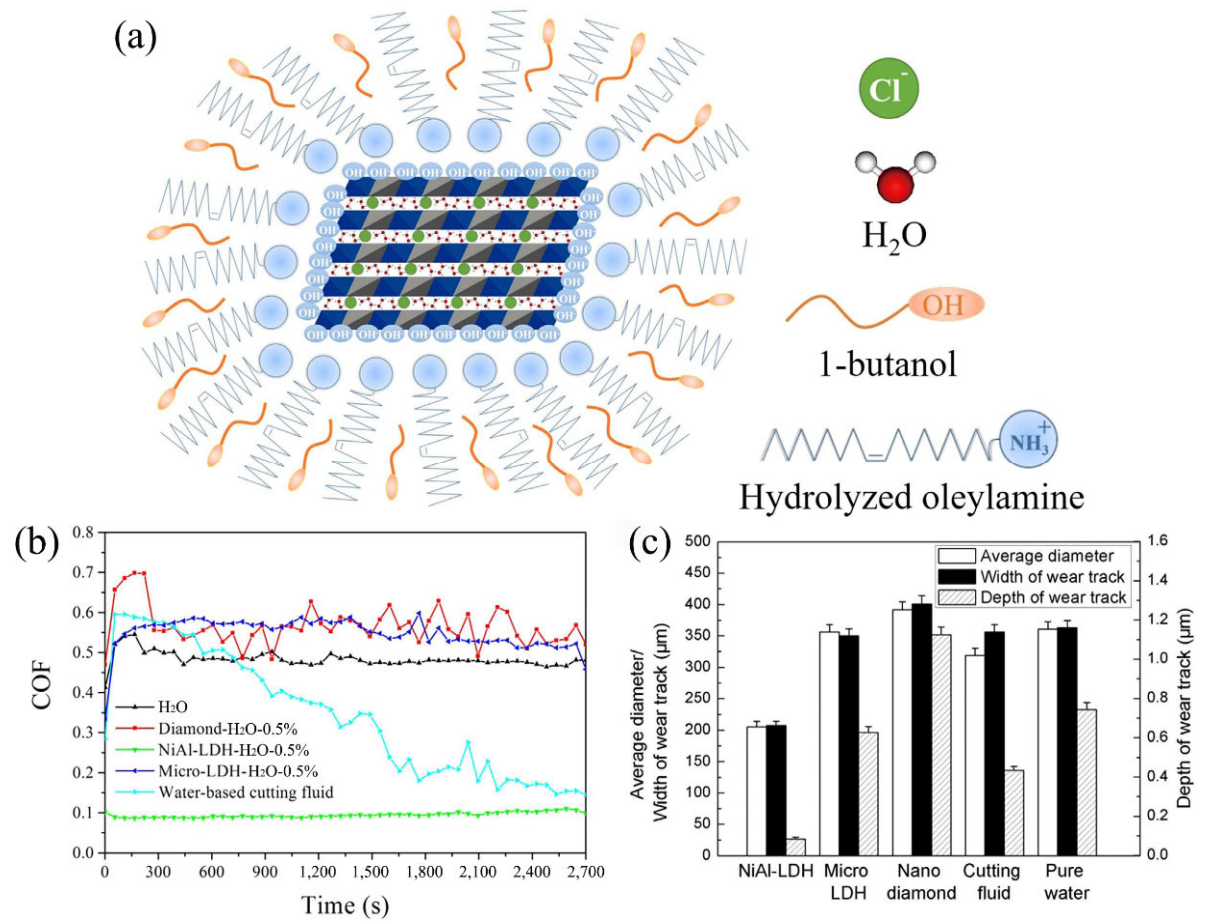

Fig. 15 Schematic model of NiAl-LDH/OAm and the results of the tribological tests of five lubricant samples, which contain the diamond nanoparticles, NiAl-LDH nanoplatelets, LDH microplatelets, water-based cutting fluid, and pure water. (a) Schematic model of NiAl-LDH/OAm. (b, c) COF and wear condition of five lubricant samples, which cover diamond nanoparticles, NiAl-LDH nanoplatelets, LDH microplatelets, water-based cutting fluid, and pure water. Reproduced with permission from Ref. [103], (C) The Author(s) 2016.

During friction testing, a lubricating layer was observed to form under a high contact pressure (initially $~ 1.5 \mathrm{GPa}$ ); this could be attributed to the small size and outstanding dispersion of the nano-additives. Figure 15(b) shows the tribological performances of various lubricants. The sample containing $0.5 \mathrm{wt} \%$ 
NiAl-LDH nanoplatelets achieved an excellent lubrication performance. Specifically, it had an $83.1 \%$ lower COF, a $43.2 \%$ lower WSD, and $88.5 \%$ and 59.5\% smaller depth and wear-track widths, respectively, than pure water. The exfoliated nanosheets exhibited a layered structure with weak interactions and a high laminate load-carrying capacity; thus, they were adsorbed on the sliding solid surfaces during friction and prevented the asperities from directly colliding with each other.

\subsection{Clay minerals}

Clay minerals represent a balance between costeffectiveness and practicability; hence, they are attracting increasing research interest as lubricant additives. One example is layered palygorskite (PAL), a natural inorganic clay mineral consisting of magnesium silicate. Because of its excellent adsorption properties and distinctive interlaminar structure, this clay mineral has been investigated in tribological and other fields. Wang et al. [104] prepared molybdenum-dotted palygorskite (Amo-PMo) nanoplatelets to enhance the specific surface area of PAL and its dispersion effect in lubricating oil. The results showed that the addition of $0.5 \%$ Amo-PMo resulted in an optimal tribological performance, achieving a COF of 0.09 . Furthermore, the wear volume and WSD reductions of the sliding ball surface were $50.4 \%$ and $37 \%$, respectively, of those lubricated with base oil. The proposed lubrication mechanism of the as-prepared Amo-PMo nanoplatelets can be explained by the self-repairing abilities of the generated $\mathrm{MoS}_{2}$ adsorbed onto the contact interface during the tribochemical reaction, as shown in Fig. 16.

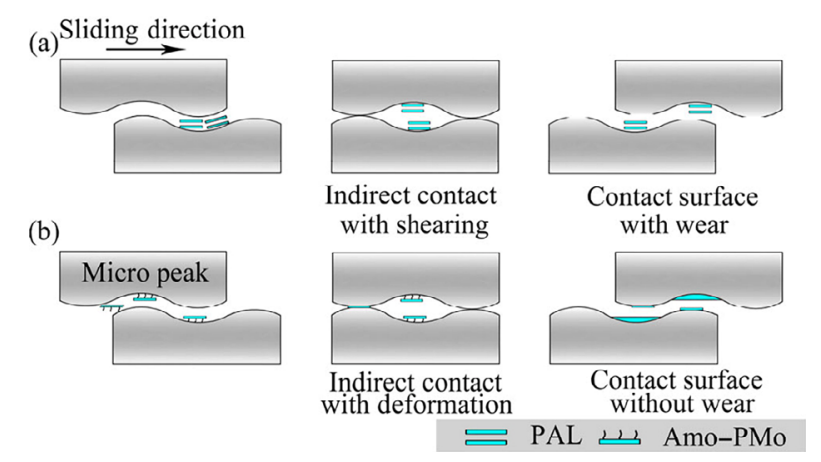

Fig. 16 Schematics of the proposed lubrication mechanism of (a) PAL and (b) Amo-PMo nanoplatelets. Reproduced with permission from Ref. [104], (C) The Author(s) 2020.
Nan et al. [10] fabricated ultrafine attapulgite powders (UAPs) with an average size of $330 \mathrm{~nm}$, using natural attapulgite powders (NAPs) and a ball-milling dispersion approach. Their investigation into the tribological performances of surface-modified UAPs and NAPs dispersed into a mineral base oil showed that both additives helped to improve the friction-reduction and anti-wear performance of the base oil. In particular, higher iron oxide and $\mathrm{SiO}$ contents were generated on the worn surface lubricated with the UAP-containing oil; this could explain the greater friction-reduction and anti-wear capabilities of the UAP.

$\mathrm{Yu}$ et al. [105] investigated the microstructure, micromechanical properties, and tribological behaviors of the tribo-film formed when serpentine ultrafine powders with an average size of $1 \mu \mathrm{m}$ were used as additives. A nanocrystalline tribo-film primarily composed of $\mathrm{Fe}_{3} \mathrm{O}_{4}, \mathrm{FeSi}, \mathrm{SiO}_{2}, \mathrm{AlFe}$, and $\mathrm{Fe}-\mathrm{C}\left(\mathrm{Fe}_{3} \mathrm{C}\right)$ compounds, with a thickness of 500-600 nm, was detected on the worn surface after lubrication with oil containing $1.5 \mathrm{wt} \%$ serpentine. As identified by the phenomenological model constructed for the tribo-film (Fig. 17), the decrease in friction and wear in the boundary and mixed-lubrication regime was attributable to multiple factors, including the remarkable mechanical properties and porous structures of the tribo-film and the reinforced phase of the embedded particles.

Rudenko et al. [106] investigated talc powder as an extreme-pressure additive for lubrication oils at various temperatures and concentrations. The optimal lubrication performance was obtained at a temperature of $100{ }^{\circ} \mathrm{C}$ and a concentration of $0.15 \mathrm{wt} \%$, where the dynamic and static COFs were reduced by over $30 \%$ compared to the reference lubricating oil alone. The results indicate that a transfer film was generated on the metal surface at high temperatures, which may decrease both the friction and wear of the contact

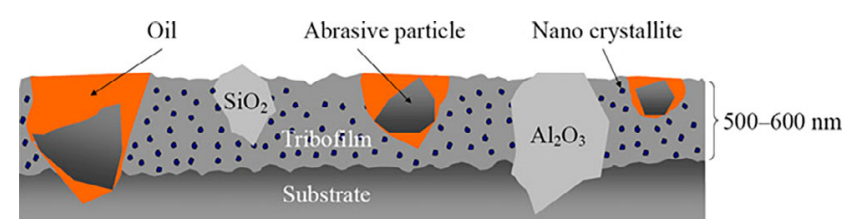

Fig. 17 Phenomenological model of the tribofilm generated by serpentine additive. Reproduced with permission from Ref. [105], (C) Elsevier 2012. 
surfaces; however, no such film was observed at room temperature.

\subsection{Hexagonal boron nitride}

Hexagonal boron nitride (h-BN) is a soft material that has received increased attention because of its various unique characteristics [107-110]. In h-BN, the atomic layers consist of $2 \mathrm{D}$ arrays of boron and nitrogen atoms, in which a covalent and extremely firm bond persists between the nitrogen and boron atoms within the sheet. However, the inter-layer bonds are fragile and primarily controlled by van der Waals interactions. The strong intralayer covalent bond between boron and nitrogen provides them with a high tensile strength and stiffness [111, 112], both of which facilitate the continuous utilization of this material under high contact pressures. This behavior is critical for enhancing the friction-reduction and anti-wear performance of this material during the sliding friction process. In contrast, the van der Waals interaction between the loosely stacked h-BN sheets is weak and therefore prone to shearing along the basal plane of the crystalline lamellar structure when subjected to sliding pressure; this provides an outstanding lubricating effect [107, 113]. Numerous studies have been conducted on the lubrication performance of h-BN. Çelik et al. [114] fabricated h-BN particles via a special process and examined the tribological behavior of these particles as additives in engine oil. According to their experimental results, the COF and wear rate were reduced by up to $14.4 \%$ and $65 \%$, respectively. A study by Charoo and Wani [115] verified that adding $\mathrm{h}-\mathrm{BN}$ nanoparticles to engine oil could significantly improve the engine oil's resistance to friction and abrasion. The results revealed that the WSD and wear loss were reduced by $20 \%$ and $70 \%$, respectively, compared to the case without additives.

Although h-BN particles offer excellent tribological performances when used as lubricating additives, they exhibit inadequate dispersion stability when placed in lube media; this severely hinders their application in tribology [116]. To address this problem, researchers have attempted to improve the dispersion stability of h-BN particles through the addition of dispersants. Gupta et al. [117] discovered that the dispersibility of variously sized h-BN particles was remarkably improved when polyisobutylene succinimide was added as a dispersant to the base oil. Moreover, they examined the influence of particle size on the tribological performance. The results suggested that, in terms of wear resistance, nano-sized h-BN particles outperformed micro-sized ones. In addition, surface modification of h-BN particles has also been found to effectively improve the dispersion stability [118]. Wang et al. [116] synthesized h-BN particles that were modified with the silane coupling agent A-151. The modified h-BN particles exhibited improved dispersion stability and lipophilicity compared to unmodified ones. This was attributed to the lipophilic vinyl groups generated on the surfaces of the h-BN particles. Tribological tests showed that adding modified h-BN particles to castor oil could realize an excellent friction-reduction and anti-wear performance under different working conditions.

Generally, the bulky size and inadequate dispersion stability of h-BN make it difficult to apply as a lubricant additive. Because of their extraordinary lubrication performance, single- or few-layered h-BN nanosheets (h-BNNSs) have been extensively investigated, to determine their applicability as liquid lubricants. Ma et al. [119] obtained two- or three-layered h-BNNSs by exfoliating bulk h-BN powders using a mixed solution of $\mathrm{NaOH}$ and $\mathrm{KOH}$ under hydrothermal treatment and sonication (Fig. 18). The h-BNNSs exhibited a better dispersibility than bulk h-BN in the base oil. The friction- and wear-testing results showed that the addition of h-BNNSs to base oil reduced the COF and WSD by $\sim 35.7 \%$ and $35.2 \%$, respectively. Using benzyl benzoate-assisted ball milling, Deepika et al. [109] fabricated h-BNNSs from disk-shaped h-BN particles. They found that the base oil containing the resulting h-BNNSs exhibited excellent wear resistance and friction-reduction capabilities. The above-mentioned studies have shown that h-BN nanosheets can serve as an effective additive in lubricants.

It is well known that the excessively strong polarities of the interlayers between h-BNNSs can inhibit interlayer slippage and impair their friction-reduction performance [120]. In addition, the compatibility between h-BNNSs and base oils is poor, which causes 


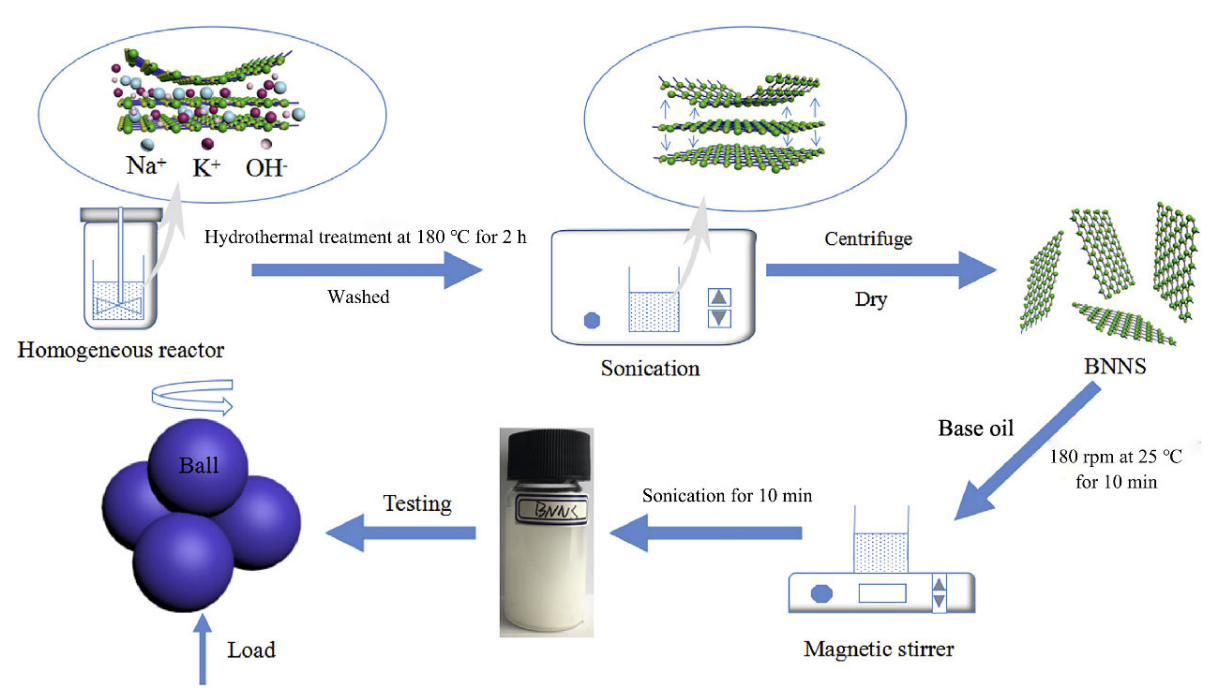

Fig. 18 Schematic illustration of preparation process and performance testing of as-exfoliated BNNSs. Reproduced with permission from Ref. [119], C Elsevier 2019.

agglomeration and can weaken the tribological performance [108]. Chemical functionalization is deemed to be the most effective method for inhibiting h-BN nanosheet agglomeration and ensuring that they disperse stably in liquid-form lubricants. Grafting organic moieties on h-BN nanosheets not only changes their surface energy but also dominates their interactions with the dispersing solvents [107]. Kumari et al. [108] found that chemically functionalized h-BN nanoplatelets could deliver enhanced friction-reduction and anti-wear performances after grafting with long alkyl chains.

\subsection{Black phosphorus}

Black phosphorus (BP) is emerging as a unique material and has attracted much scientific attention [121, 122]. In particular, BP exhibits weak interlayer interactions, an anisotropic lamellar structure, high thermal stability, a tunable bandgap, and high carrier mobility; this makes it suitable as a liquid lubricant additive in numerous applications, including tribology [123-125]. Owing to its low shear strength and high thermal stability, few-layer BP has become a promising candidate additive for lubrication. Wang et al. [124] reported a number of recent developments in the tribological performances of BP nanosheets, including their micro-friction properties and lubrication mechanisms when applied as additives in both waterand oil-based lubricants. In addition, for comparison purposes, they examined the tribological performances of GO and $\mathrm{MoS}_{2}$ nanosheets when added to oil-based lubricants, as shown in Fig. 19. When applied as additives for oil-based lubricants, the BP dispersions achieved similar lubrication performances at low loads; however, they showed excellent capacities to resist extreme pressure and carry large loads, as shown in Fig. 20. Wu et al. [125] investigated the nanofriction properties of degraded BP sheets against a silicon nitride tip. Reduced friction was observed in the degraded area of the BP nanosheets, and significant improvements were achieved in the lubrication behaviors of the BP flakes, because of ambient degradation. Notably, a synergetic effect was realized between water and the chemical groups generated on the oxidized surface; this may account for the reduced friction of the degraded BP flakes. The tribological performance of BP in combination with polytetrafluoroethylene-based composites was investigated by Lv et al. [126]. Their experimental results showed that BP significantly reduced the wear rate of the composites. The lubrication mechanism of BP was considered to be transfer-film generation on the contact interface.

Generally, the ambient instability of BP impedes its practical application. To address this problem, strategies such as protection by passivation layers [127], modification with organic compounds [128], and enhancement with metal nanoparticles [129] have been proposed. Studies on nanocomposites containing BP as lubricant additives will be discussed in detail in 

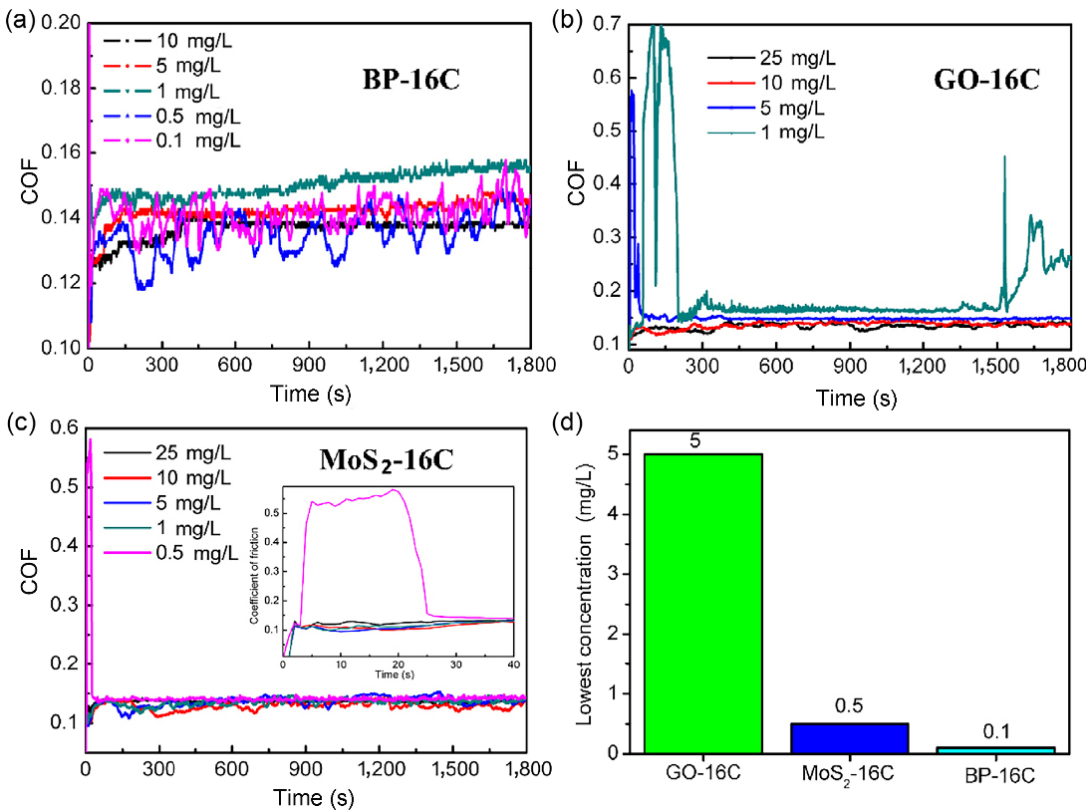

Fig. $19 \mathrm{COF}$ of BP-16C at different concentrations: (a) COF of BP-16C below $10 \mathrm{mg} / \mathrm{L}$; (b) COF of GO-16C below $10 \mathrm{mg} / \mathrm{L}$; (c) COF of MoS2-16C below $10 \mathrm{mg} / \mathrm{L}$. (d) Comparison of three oil-based lubrication additives at ultra-low concentration. Reproduced with permission from Ref. [124], (C) The author(s) 2018.
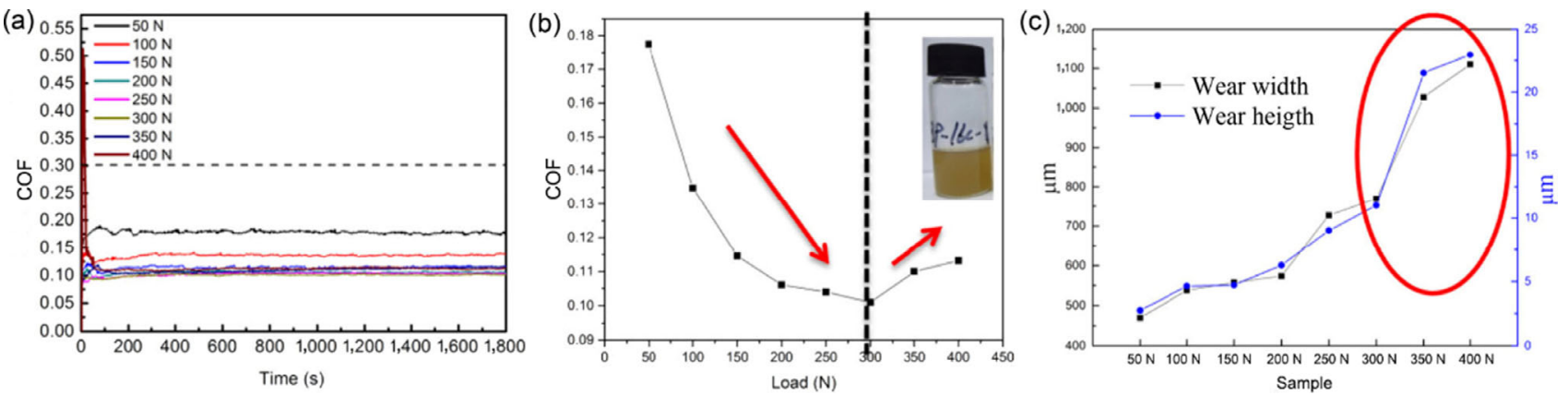

Fig. 20 Friction properties of BP-16C at various loads: (a) COF of BP-16C at various loads; (b) the change trend of steady COF; (c) wear width and wear height of lower samples (disc). Reproduced with permission from Ref. [124], (C) The author(s) 2018.

\section{Section 5.7.}

Furthermore, BP has performed well as a lubricant additive in the field of superlubricity in recent years, and it has come to be preferred by many researchers. Wang et al. [130] indicated that BP nanosheets modified by $\mathrm{NaOH}$ could achieve superlubricity when functioning as water-based lubricant additives. Ren et al. [131] fabricated BP quantum dots (BPQDs) with an average lateral size of $6.5 \pm 3 \mathrm{~nm}$ and a thickness of $3.4 \pm 2.6 \mathrm{~nm}$; these were dispersed in ethylene glycol (EG) to study macroscale superlubricity. The wear rate under lubrication from the BPQD-EG aqueous suspension at the $\mathrm{Si}_{3} \mathrm{~N}_{4} /$ sapphire frictional interface was measured to be $5.96 \%$ that obtained for the EG aqueous solution lubricant, and it achieved a macroscale superlubricity state under a high contact pressure of $336 \mathrm{MPa}$. It is believed that the outstanding anti-wear and lubrication effect was jointly caused by the rolling effect of BPQDs, the low shear stress between the BPQD interlamination, and the oxidative products of BPQDs.

\subsection{Nanocomposites for synergistic effects}

Taking full advantage of the synergistic effects of multiple nanomaterials is critical for developing efficient lubricating materials. Because of the synergetic effects of multiple types of nanoparticle, composites generally exhibit superior performances to individual nanoparticles [132, 133]. Gong et al. [134] prepared 
nanocomposites containing $\mathrm{MoS}_{2}$ nanoparticles grown on carbon nanotubes $\left(\mathrm{MoS}_{2} @ \mathrm{CNT}\right)$, graphene $\left(\mathrm{MoS}_{2} @ \mathrm{Gr}\right)$, and fullerene $\mathrm{C} 60\left(\mathrm{MoS}_{2} @ \mathrm{C} 60\right)$, to develop additives suitable for lubrication at high temperatures. According to their experimental results, all as-prepared composites exhibited a better dispersibility in base oil than the pure $\mathrm{MoS}_{2}$ nanoparticles, leading to a remarkable reduction in friction and wear compared to the CNT, Gr, C60, and $\mathrm{MoS}_{2}$ nanoparticles. These improvements could be explained by the synergistic effects of $\mathrm{MoS}_{2}$ and carbon nanomaterials. Ren et al. [135] synthesized three morphological $\mathrm{ZnO}$ nanoparticles to prepare ZnO@graphene core-shell nano-additives (the so-called "coated nanocomposites") for lubricants; these feature a hard core and soft shell. They suggested that sheetlike $\mathrm{ZnO}$ had a more satisfactory morphology, and the hard-core/soft-shell nanostructure of ZnO@graphene was more suitable for dynamic friction environments. Such remarkable tribological performances and sustained load capacities were ascribed to the synergistic effect, as illustrated in Fig. 21. Hou et al. [136] performed tribological research on lanthanum trifluoride-graphene oxide $\left(\mathrm{LaF}_{3}-\mathrm{GO}\right)$ nanohybrids. According to their results, by using the synergistic effects of $\mathrm{LaF}_{3}$ and $\mathrm{GO}, \mathrm{LaF}_{3}-\mathrm{GO}$ nanohybrids could enhance the tribological properties of distilled water. Furthermore, the researchers prepared oleic-acidsurface-modified lanthanum trifluoride-graphene oxide $\left(\mathrm{OA}-\mathrm{LaF}_{3}-\mathrm{GO}\right)$ nanohybrids, to improve the poor dispersion and stability of $\mathrm{LaF}_{3}-\mathrm{GO}$ nanohybrids in the base oil [137]. In the tribological experiments, the optimal friction-reduction and anti-wear capabilities were achieved by adding $0.5 \mathrm{wt} \% \mathrm{OA}-\mathrm{LaF}_{3}-\mathrm{GO}$ nanohybrids, as opposed to liquid paraffin alone; this was considered responsible for the ability of $\mathrm{OA}-\mathrm{LaF}_{3}-\mathrm{GO}$ to transfer to the rubbed steel surface and decompose to generate protective layers.

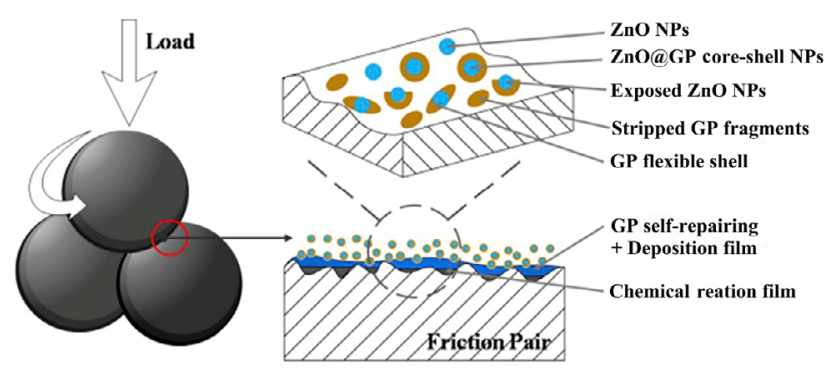

Fig. 21 Schematic of lubricating mechanism of nanoadditives. Reproduced with permission from Ref. [135], C Elsevier 2019.
Zheng et al. [138] studied the tribological performance of $\mathrm{Fe}_{3} \mathrm{O}_{4} / \mathrm{MoS}_{2}$ nanocomposites. They found that the COFs and WSDs of the steel balls decreased significantly when the concentration of $\mathrm{Fe}_{3} \mathrm{O}_{4} / \mathrm{MoS}_{2}$ nanocomposites was increased in both aqueous and bio-diesel media. The $\mathrm{Fe}_{3} \mathrm{O}_{4}$ nanoparticles were well dispersed on the $\mathrm{MoS}_{2}$ nanosheets, which was considered responsible for the remarkable lubrication performance. Additionally, a synergistic effect was imposed by the nanoball-bearing role of the $\mathrm{Fe}_{3} \mathrm{O}_{4}$ nanoparticles, the slipping role of the $\mathrm{MoS}_{2}$ nanosheets, and the adsorbed tribo-film; this contributed to the reduced friction and wear of the friction pairs.

$\mathrm{Cu}$ nanoparticles have been employed as metalcladding modifiers for nano-lamellar $\mathrm{WS}_{2}$ particles [139]. These nanocomposite lubricants were found to alter the COF of the initial lubricant whilst also greatly improving its wear resistance. An explanation for these tribological performance enhancements may be the joint effect of the nano-lamellar $\mathrm{WS}_{2}$ and metalcladding additives of $\mathrm{Cu}$ nanoparticles. Padgurskas et al. [3] conducted tribological studies on mineral oils containing $\mathrm{Fe}, \mathrm{Cu}$, and $\mathrm{Co}$ nanoparticles and combinations thereof. According to their tribological tests, these nanoparticles and their combinations all significantly reduced the friction and wear on the mating surfaces, with $\mathrm{Cu}$ nanoparticles and their combinations being the most effective.

Wu et al. [140] explored the effects of temperature, contact pressure, and composite concentration on the tribological performance of the nano-lanthanum hydroxide/reduced GO [nano- $\mathrm{La}(\mathrm{OH})_{3} / \mathrm{RGO}$ ] composites used in diesel engine oil. Their results showed that nano- $\mathrm{La}(\mathrm{OH})_{3} / \mathrm{RGO}$ composites could substantially enhance the anti-wear capabilities of diesel engine oil. Significantly, the anti-wear capabilities of diesel engine oil were increased by $44 \%$ after $0.1 \mathrm{wt} \%$ composites were added at a contact pressure of $1.62 \mathrm{GPa}$ and a temperature of $80{ }^{\circ} \mathrm{C}$. They proposed a synergistic wear-resistance mechanism for graphene and lanthanum oxide, based on the worn surface characterization. Zhao et al. [101] fabricated $\mathrm{La}(\mathrm{OH})_{3}$ nanoparticles and serpentine/La(OH) composite particles, to comparatively investigate the tribological performances of different samples. The serpentine, $\mathrm{La}(\mathrm{OH})_{3}$, and serpentine $/ \mathrm{La}(\mathrm{OH})_{3}$ composite particles were all shown to offer improved friction- 
reduction and wear-resistance capabilities compared to the base oil. The oil exhibited optimal frictionreduction, anti-wear, and self-repairing capabilities when composite particles were added.

Wang et al. [141] fabricated a silver/graphene nanocomposite using a one-step laser irradiation strategy. Tribological experiments showed that $0.1 \mathrm{wt} \%$ of this composite reduced the COF and WSD by $40 \%$ and $36 \%$, respectively. The excellent lubrication mechanism was attributed to the synergistic effects of the self-lubrication induced by the layered structure, the shift from sliding to rolling friction, and the selfrepairing effect of the Ag nanospheres.

Tang et al. [123] synthesized BP dotted with silver nanoparticles $(\mathrm{Ag} / \mathrm{BP})$ and investigated the tribological performances of the as-prepared $\mathrm{Ag} / \mathrm{BP}$ nanocomposites when used as lubricant additives in PAO6-based oil. When dispersed with trace amounts of $\mathrm{Ag} / \mathrm{BP}$ nanoadditives, the oil exhibited an extraordinary lubrication performance for steel/steel contacts. More specifically, the oil dispersed with $0.075 \mathrm{wt} \% \mathrm{Ag} / \mathrm{BP}$ nano-additives exhibited a 73.4\% lower COF and a $92.0 \%$ lower wear rate than the PAO6-based oil. The researchers also discussed the potential friction-reduction and wearresistance mechanisms of $\mathrm{Ag} / \mathrm{BP}$ nano-additives in oil, as shown in Fig. 22.

The previous sections primarily reviewed research dealing with the application of nano-additives in oil-based lubricants. However, a number of studies have focused on the application of nano-additives in water-based lubricants. A typical example is the study by Min et al. [142], who prepared fluorinated CNTs and modified them with urea to produce urea-modified fluorinated CNTs (UF-CNTs) offering hydrophilic functionalities. The results showed that

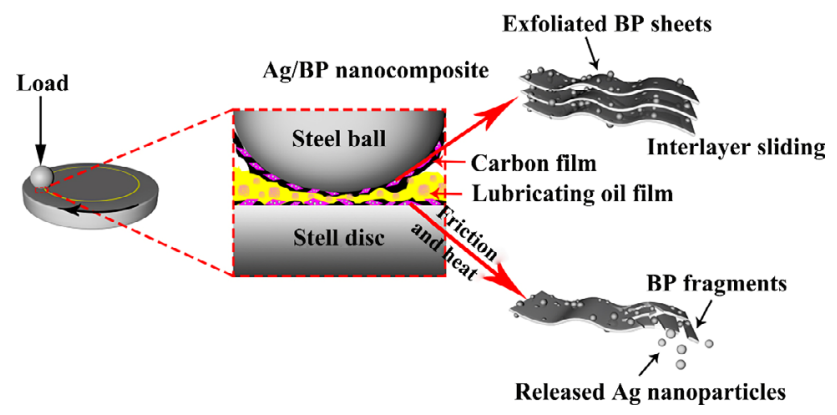

Fig. 22 Potential friction-reducing and anti-wear mechanisms of $\mathrm{Ag} / \mathrm{BP}$ nano-additives in oil. Reproduced with permission from Ref. [123], (C) Elsevier 2019. the obtained UF-CNTs could be dispersed uniformly in water for up to 12 days (Fig. 23), indicating its significant potential as a water-based additive for lubrication. Zhao et al. [143] fabricated water-soluble $\mathrm{Cu}$ nanoparticles with a size of $3 \mathrm{~nm}$ at room temperature (around $25{ }^{\circ} \mathrm{C}$ ) through in-situ surface modification. A tribological experiment was performed to determine the applicability of these $\mathrm{Cu}$ nanoparticles as additives in distilled water for a friction pair consisting of a GCr15 steel ball and silicon wafer. The results suggested significant improvements in the tribological performance of the distilled water. More specifically, the optimal COF (0.06) was achieved when $0.6 \mathrm{wt} \% \mathrm{Cu}$ nanoparticles were added to the distilled water, achieving $80.6 \%$ less friction and wear than that obtained by lubrication with the base fluid alone.

\section{Discussion}

The lubrication mechanisms of the aforementioned lubricating additives can be summarized into four categories: ball-bearing effects, film-formation mechanisms, mending or self-repairing effects, and polishing effects. Meanwhile, the tribological performances of lubricant additives are determined by

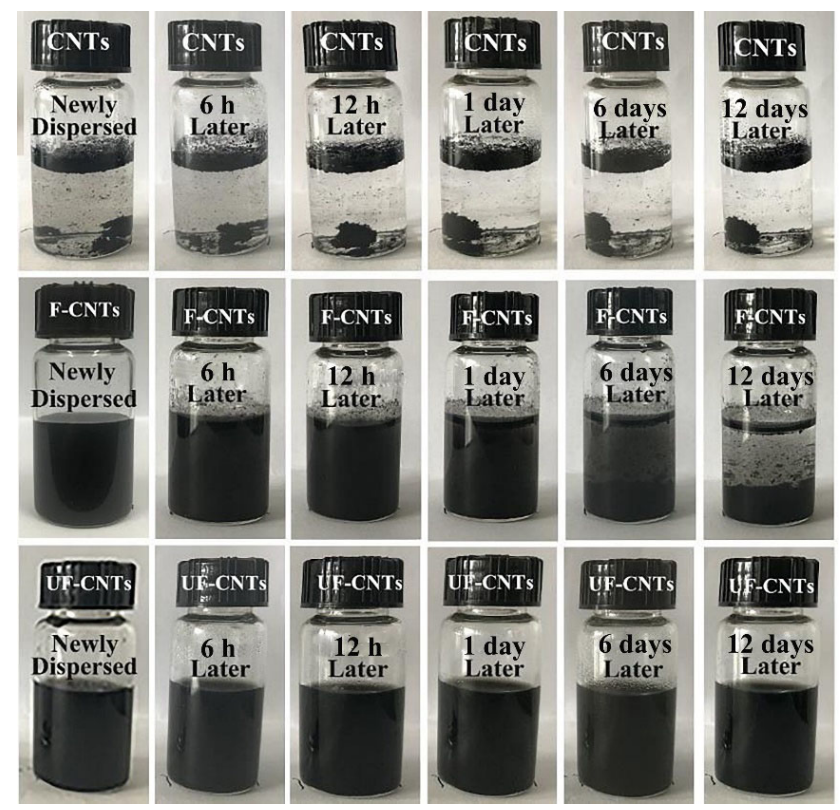

Fig. 23 Dispersion properties of $0.15 \mathrm{wt} \% \mathrm{CNTs}, 0.15 \mathrm{wt} \%$ F-CNTs, and $0.15 \mathrm{wt} \%$ UFCNTs in the water. Reproduced with permission from Ref. [140], (C) Elsevier 2019. 
numerous factors, and challenges remain to be addressed before nanoparticles can be used in lubrication applications. This is discussed in detail here.

\subsection{Lubrication mechanisms}

\subsubsection{Ball-bearing effect}

Spherical and quasi-spherical nanoparticles typically serve as tiny ball bearings that roll into the contact zone and convert the sliding friction to a combination of sliding and rolling frictions. In particular, the rolling effects of sphere-like $\mathrm{CuO}$ nanoparticles between contact surfaces can strengthen the tribological performances of base fluids [5, 144]. The addition of a nano-lubricant can result in excellent product quality, because the rolling action of nanoparticles between sliding surfaces prevents surface contact [145]. Analysis of $\mathrm{ZnO}$ composite submicrospheres containing $\mathrm{Al}_{2} \mathrm{O}_{3}$ nanoparticles, when applied as additives for lubricating oils, has shown that rolling friction comes to dominate over sliding friction, and these composite particles are then squeezed into the grooves on the friction surfaces, which helps to reduce wear [146]. Copper oxide nanoparticles can transform sliding friction into rolling friction, thereby reducing the effective COF [147].

\subsubsection{Film-formation mechanism}

Nanoparticles with large surface areas promote chemical activities and can be rapidly adsorbed onto a friction surface to generate a physical adsorption film. Several nanoparticles are influenced by external factors relating to friction surface migration and are deposited on the contact interface to generate a deposited film. A chemical reaction film can be generated by the chemical reactions of nanoparticles on the friction surface, thereby improving the abrasive resistance of the friction-pair surface [148]. The protective film formed on the contact surface is also referred to as a tribo-film; its material composition determines the tribological performance of the contact surface. Film formation is stimulated by reactions between the treated materials and additives under ambient conditions or tribo-sintering [2, 149]. Several studies have discussed the optimal tribo-film formation mode. To protect worn surfaces, the tribo-film formation rate should exceed the wear-removal rate
[150, 151]. As described in Refs. [3, 152, 153], the lubrication mechanism of metallic nanoparticles consists of their deposition on the worn surface to form a thin layer, which is typically more ductile than the substrate; this reduces friction by lowering the sliding resistance, and it protects the substrate from wear by inhibiting direct metal-to-metal contact. The tribo-film formation mode is shown in Fig. 24; it guarantees surface protection and protects the material against crack propagation by reducing the direct contact between asperities [2].

\subsubsection{Mending or self-repairing effect}

The mending or self-repairing effect can be explained as nanoparticle deposition on the friction surfaces and mass-loss compensation. In this process, nanoparticles are deposited on the worn friction surface and fill the scars and grooves to decrease wear. A study into how $\mathrm{CuO}$ and $\mathrm{Al}_{2} \mathrm{O}_{3}$ nanoparticle-based nano-lubricants affect the surface quality during the formation process found that nano-lubricants can better improve the surface roughness than traditional lubricants [154]. Suspensions of surface-modified $\mathrm{CuO}$ nanoparticles in bio-based lubricants exhibit considerable extremepressure properties in terms of the load wear index and low-cylinder liner wear, owing to their surfacerepairing effect [145].

\subsubsection{Polishing effect}

The polishing effect, also known as the smoothing effect, occurs when the lubricating surface is smoothened by abrasive treatment using nanoparticles. During the friction process, nanoparticles fill the gaps of rough asperities to act as reservoirs of the solid lubricants (nanoparticles) in contact. The process by which rough valleys are filled is referred to as the

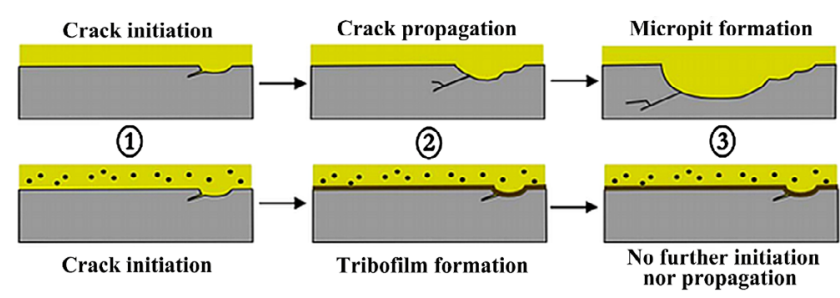

Fig. 24 Lubrication by base oil alone (top), and tribo-film formation and surface protection by nanoparticles (bottom). Reproduced with permission from Ref. [2], (C) Springer Nature 2016. 
"smoothing-out" process. This "artificial smoothing" or polishing mechanism can help reduce surface roughness and thereby enhance tribological properties [155].

The mechanisms that describe how nanoparticles contribute to friction reduction and wear resistance are shown in Fig. 25.

\subsection{Factors affecting the tribological performances of nano-lubricant additives}

\subsubsection{Effects of nanoparticle size}

The tribological performances of nano-lubricants depend directly on the nanoparticle size. More specifically, the nanoparticle sizes determine the internal mechanical and physico-chemical properties of nanolubricants; these, in turn, determine the tribological properties. By the Stokes' law [28], smaller sizes imply improved dispersion stability and tribological characteristics. The effect of nanoparticle size on the nano-lubrication mechanisms of $\mathrm{CuO}$ nanoparticles added to synthetic oil was investigated for three different sizes: $2.5,4.4$, and $8.7 \mathrm{~nm}$ [156]. The smallest nanoparticle size was found to correspond to the lowest COF. The optimal results were achieved for a nano-lubricant with a nanoparticle size of $2.5 \mathrm{~nm}$.

\subsubsection{Effects of nanoparticle morphology}

The shape of the nanoparticles used as lubricant additives is another key consideration in nanolubricant design because it directly determines the pressure to which the nanoparticles are subjected during loading. Nanoparticles have five different

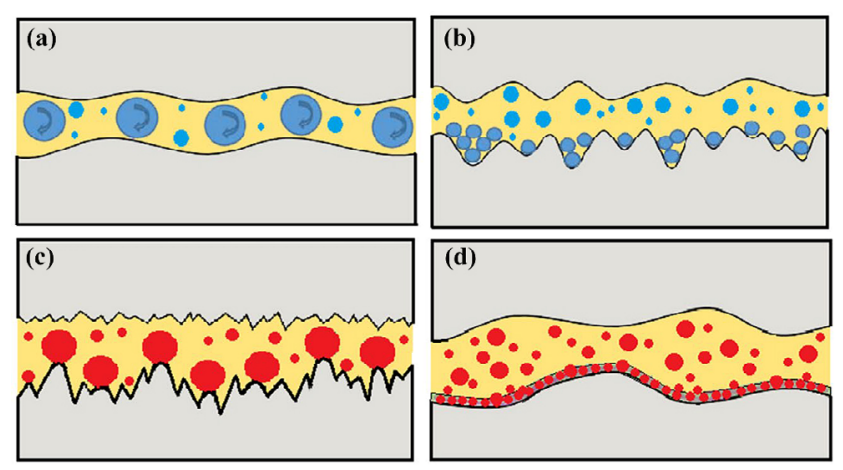

Fig. 25 Different mechanisms for improving tribological properties using nanoparticles: (a) rolling mechanism; (b) mending mechanism; (c) polishing mechanism; (d) protective film. Reproduced with permission from Ref. [157], (C) Taylor \& Francis 2018. shapes: granular, onion, sheet, spherical, and nanotube. Statistics show that the spherical shape is the most common, followed by the granular, sheet, onion, and tube shapes, respectively, as shown in Fig. 26.

Onion, leaf, and spherical morphologies exhibit outstanding tribological characteristics. Spherically shaped nanoparticles offer high load capacities and extreme-pressure characteristics; this is because of their ball-bearing effect, which can convert sliding friction to rolling friction and thereby facilitate friction reduction [158]. The sphere-like nanoparticles realize point contact with the counter surface. Nanosheets are associated with line contact, whereas nanoplatelets are characterized by planar contact.

\subsubsection{Effects of surface functionalization}

Functionalization of the nanoparticle surface can effectively regulate the colloidal stability of nanoparticle dispersion and increase the lubricity of most nanoparticle layers. Non-functionalized nanoparticles are understood to be prone to aggregation in inert nonpolar liquids. Typically, such aggregation is prevented by protecting the nanoparticles with steric or electrostatic stabilization; this is typically achieved by coating the nanoparticles with a polymer or surfactant [28]. Typically, nanoparticle surface functionalization is essential to enhancing the colloidal stability and homogeneous distribution of nanoparticles in base oils.

Ni-based nano-lubricants - featuring oleylamine and oleic acid as surface-capping agents in a polyalpha-olefin base oil or a synergistic lubricant system with a solid-liquid [159]-offer excellent wear resistance, even at low $\mathrm{Ni}$ concentrations (0.05 wt\%). This is because surface-capped Ni nanoparticles in

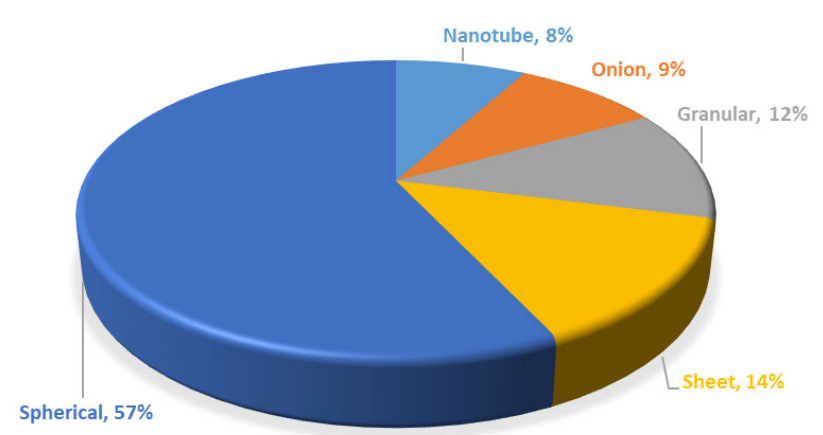

Fig. 26 Statistics of nanoparticle morphology. Reproduced with permission from Ref. [160], (C) Elsevier 2016. 
nanolubricants can release highly active $\mathrm{Ni}$ nanocores and $\mathrm{O}-$ and $\mathrm{N}$-containing organic modifying agents, which can easily generate boundary lubrication films on sliding steel surfaces.

When dispersed in 60SN base oil, poly-alpha olefin, or diisooctyl sebacate [161], oleic-acid-surface-modified $\mathrm{ZnO}$ nanoparticles can significantly reduce friction and wear. Notably, when the quantity of added oleic acid was $8 \mathrm{wt} \%$ and that of the $\mathrm{ZnO}$ nanoparticles was $0.5 \mathrm{wt} \%$, the COF and the average WSD were minimized, and the nano-lubricant exhibited optimal friction-reduction and wear-resistance capabilities. It seems promising to use nano-lubricants based on multiwalled CNTs and $\mathrm{ZnO}$ nanoparticles dispersedalong with gum arabic surfactant - at volume fractions of $0.005 \%$ and $0.02 \%$, respectively, in SAE $20 \mathrm{~W} 40$ engine oil [162].

\subsubsection{Effects of nanoparticle concentration}

Concentration is another key factor affecting the lubrication performance of nano-lubricants [163]. Typically, the presence of nanoparticles helps to decrease friction and abrasion, even at concentrations below $1 \mathrm{wt} \%$ [3] and higher than $2 \mathrm{wt} \%$ [153], indicating that nanoparticles do not have a perfect concentration. Moreover, uncertainties remain regarding the relationship between the concentration of nano-additives and their effects on friction and abrasion. Notably, an optimal concentration can be found at which minimal COF can be realized. However, this is largely dependent on the system, because the lubricant composition must be adjusted to satisfy each operating condition [164]. For instance, identical $\mathrm{MoS}_{2}$ nanoparticles have exhibited different appropriate concentrations for two different types of base fluids (i.e., $0.53 \mathrm{wt} \%$ for coconut oil and $0.58 \mathrm{wt} \%$ for mineral oil) [163].

\subsection{Challenges for nanoparticles in lubrication applications}

Although inorganic nanoparticles can improve the tribological properties of base lubricants, limitations still remain when translating them into practical applications. Because of their high specific surface areas and surface energy values, inorganic nanoparticles easily agglomerate in liquid media. When making contact with the friction surface, these particles produce an abrasive effect that may aggravate the friction surface wear and consequently prevent efficient work. For instance, He et al. [165] found that excessive copper nanoparticles can increase the COF and WSD and subsequently degrade the lubrication performance of grease. Wu et al. [166] found that a high concentration of $\mathrm{TiO}_{2}$ (exceeding $0.8 \mathrm{wt} \%$ ) in lubricants could result in agglomeration and thereby increase the COF. Lijesh et al. [167] observed that the agglomeration of MWCNTs could significantly damage their performance and result in increased wear on the surface. Methods for stabilizing nanoparticles can be applied during the preparation process. The level of aggregation depends on various factors and is controlled by the synthesis conditions. It can be difficult to identify an effective inert medium for nanoparticles (especially those sized 1-10 nm) with high surface energies.

Additionally, major challenges remain in nanoparticle preparation. Currently available studies on nanoparticle-based lubricant additives predominately remain in the experimental stages, and there is still a long way to go before large-scale preparation and practical applications can be realized.

\section{Conclusions and prospects}

Inorganic nanoparticles exhibit friction-reducing and anti-wear capacities, owing to their unique structure and nature; as a result, they present attractive prospects for the development of nanoscale lubricant additives. In this paper, we comprehensively reviewed studies on the tribological performances of inorganic nanoparticle additives in base fluids; we found that appropriate inorganic nanomaterials, when used as lubricant additives, can inhibit severe wear on solid surfaces and enhance tribological performances. The lubrication mechanisms are mainly categorized into ball-bearing effects, film-formation mechanisms, mending or self-repairing effects, and polishing effects. The tribological performances of nano-lubricant additives are predominately influenced by their size, morphology, surface functionalization, and concentration. Finally, we conclude that the promotion of inorganic nanomaterials as additives in lubrication applications will require increased efforts in the following areas. 
1) The design and preparation of novel inorganic material lubricant additives that possess special structures (e.g., two-dimensional materials) and outstanding tribological properties should be investigated. On one hand, it is necessary to develop new lubricant additives with multiple functionalities, including antifriction, anti-wear, high-temperature resistance, anti-oxidation, corrosion resistance, and viscosity enhancement. On the other hand, it is necessary to fully exploit the synergistic lubrication effects of composites consisting of two or more materials, through the use of reasonable combinations. The effects of the variety, concentration, and individual morphologies of each additive on the tribological performance of the resulting lubricants must be studied.

2) Further exploration into the lubrication mechanisms of nanoparticles-using modern analytical methods and simulation technologies (both experimental and theoretical)-is required. Different mechanisms determine the friction and wear reductions realized by inorganic nanoadditives. However, the interaction of additives with lubricants, and the relationship between inorganic nanoparticles and rubbing surfaces (energy, catalysis, rubbing surface morphology, etc.) remain unclear; furthermore, the formation and changes of tribo-films or lubrication films and physicochemical reactions on the rubbing surfaces are not thoroughly understood. In addition, studies considering the variations in the movement and migration of nanofluids on lubricants, as well as molecular dynamics simulations of the anti-wear and friction reductions, are still required. Investigations on these subjects may illuminate lubrication mechanisms involving inorganic nanomaterial additives and facilitate the development of controllable modification and functionalization approaches for these additives.

3) The study of superlubricity is a recent trend in the field of tribology. Such research may facilitate progress in industrial and energy applications; therefore, further research is needed to realize superlubricity through the use of inorganic nanoparticles as lubricant additives in base fluids.

4) Lubricant additives for harsh working conditions are increasingly needed, following the rapid development of the aerospace industry. Studies on the tribological performances of inorganic lubricant additives for elevated temperatures, extreme pressures, high speeds, heavy loads, and high-vacuum conditions may contribute to a more comprehensive understanding of tribology under harsh conditions, and may further accelerate progress in aerospace and energy.

5) The applications of numerous inorganic nanoparticles in lubricant additives are limited by their poor dispersion and stability in base fluids. Effective modification and functionalization methods are required to improve the dispersity of nanoparticles in base fluids and to provide the lubricants with new capabilities (e.g., bearing capacity); this may require extensive exploration of new approaches, to equip inorganic nanoparticles with the desired tribological properties.

\section{Acknowledgements}

The authors are very grateful to the financial supports by the National Natural Science Foundation of China (51805336, 11604224, and 61973224), the Natural Science Foundation of Liaoning Province (20170540740, 20180550861, 2019-ZD-0670, and 2019-ZD-0687), the Scientific Research Project of Education Department of Liaoning Province (lnjc201918), the Tribology Science Fund of State Key Laboratory of Tribology (SKLTKF16B07), and the Open Fund of Shenyang Key Laboratory of Aero-engine Materials Tribology (SKLAMT201901).

Open Access This article is licensed under a Creative Commons Attribution 4.0 International License, which permits use, sharing, adaptation, distribution and reproduction in any medium or format, as long as you give appropriate credit to the original author(s) and the source, provide a link to the Creative Commons licence, and indicate if changes were made.

The images or other third party material in this article are included in the article's Creative Commons licence, unless indicated otherwise in a credit line to the material. If material is not included in the article's Creative Commons licence and your intended use is not permitted by statutory regulation or exceeds the permitted use, you will need to obtain permission directly from the copyright holder.

To view a copy of this licence, visit http://creativecommons.org/licenses/by/4.0/. 


\section{References}

[1] Holmberg K, Erdemir A. Influence of tribology on global energy consumption, costs and emissions. Friction 5(3): 263-284 (2017)

[2] Gulzar M, Masjuki H H, Kalam M A, Varman M, Zulkifli N W M, Mufti R A, Zahid R. Tribological performance of nanoparticles as lubricating oil additives. J Nanoparticle Res 18(8): 1-25 (2016)

[3] Padgurskas J, Rukuiza R, Prosyčevas I, Kreivaitis R. Tribological properties of lubricant additives of $\mathrm{Fe}, \mathrm{Cu}$ and Co nanoparticles. Tribol Int 60: 224-232 (2013)

[4] Bogunovic L, Zuenkeler S, Toensing K, Anselmetti D. An oil-based lubrication system based on nanoparticular $\mathrm{TiO}_{2}$ with superior friction and wear properties. Tribol Lett 59(2): 1-12 (2015)

[5] Alves S M, Barros B S, Trajano M F, Ribeiro K S B, Moura E. Tribological behavior of vegetable oil-based lubricants with nanoparticles of oxides in boundary lubrication conditions. Tribol Int 65: 28-36 (2013)

[6] Gupta R N, Harsha A P. Tribological evaluation of calciumcopper-titanate/cerium oxide-based nanolubricants in sliding contact. Lubr Sci 30(4): 175-187 (2018)

[7] Kalin M, Kogovšek J, Kovač J, Remškar M. The formation of tribofilms of $\mathrm{MoS}_{2}$ nanotubes on steel and DLC-coated surfaces. Tribol Lett 55(3): 381-391 (2014)

[8] Chen L J, Zhu D Y. Preparation and tribological properties of unmodified and oleic acid-modified $\mathrm{CuS}$ nanorods as lubricating oil additives. Ceram Int 43(5): 4246-4251 (2017)

[9] Rabaso P, Ville F, Dassenoy F, Diaby M, Afanasiev P, Cavoret J, Vacher B, Le Mogne T. Boundary lubrication: Influence of the size and structure of inorganic fullerenelike $\mathrm{MoS}_{2}$ nanoparticles on friction and wear reduction. Wear 320: 161-178 (2014)

[10] Nan F, Xu Y, Xu B S, Gao F, Wu Y X, Li Z G. Tribological behaviors and wear mechanisms of ultrafine magnesium aluminum silicate powders as lubricant additive. Tribol Int 81: 199-208 (2015)

[11] He A S, Huang S Q, Yun J H, Jiang Z Y, Stokes J R, Jiao S H, Wang L Z, Huang H. Tribological characteristics of aqueous graphene oxide, graphitic carbon nitride, and their mixed suspensions. Tribol Lett 66(1): 1-12 (2018)

[12] Kumar P, Wani M F. Tribological characterisation of graphene oxide as lubricant additive on hypereutectic Al-25Si/steel tribopair. Tribol Trans 61(2): 335-346 (2018)

[13] Ali M K A, Hou X J, Mai L Q, Cai Q P, Turkson R F, Chen $\mathrm{B}$ C. Improving the tribological characteristics of piston ring assembly in automotive engines using $\mathrm{Al}_{2} \mathrm{O}_{3}$ and $\mathrm{TiO}_{2}$ nanomaterials as nano-lubricant additives. Tribol Int 103: 540-554 (2016)
[14] Mosleh M, Ghaderi M. Deagglomeration of transfer film in metal contacts using nanolubricants. Tribol Trans 55(1): 52-58 (2012)

[15] Xia W Z, Zhao J W, Wu H, Jiao S H, Zhao X M, Zhang $\mathrm{X}$ M, Xu J Z, Jiang Z Y. Analysis of oil-in-water based nanolubricants with varying mass fractions of oil and $\mathrm{TiO}_{2}$ nanoparticles. Wear 396-397: 162-171 (2018)

[16] Kumara C, Luo H M, Leonard D N, Meyer H M, Qu J. Organic-modified silver nanoparticles as lubricant additives. ACS Appl Mater Interfaces 9(42): 37227-37237 (2017)

[17] Meng Y, Su F, Chen Y. Supercritical fluid synthesis and tribological applications of silver nanoparticle-decorated graphene in engine oil nanofluid. Sci Rep 6: 31246 (2016)

[18] Ghaednia H, Hossain M S, Jackson R L. Tribological performance of silver nanoparticle-enhanced polyethylene glycol lubricants. Tribol Trans 59(4): 585-592 (2016)

[19] Song H J, Huang J, Jia X H, Sheng W C. Facile synthesis of core-shell Ag@C nanospheres with improved tribological properties for water-based additives. New J Chem 42(11): 8773-8782 (2018)

[20] Guzman F L, Ribeiro S J, Monteiro L M S, Kalab A J. Experimental investigation of the tribological behavior of lubricants with additive containing copper nanoparticles. Tribol Int 117: 52-58 (2018)

[21] Zhang Y J, Zhang S M, Sun D E, Yang G B, Gao C P, Zhou C H, Zhang C L, Zhang P Y. Wide adaptability of $\mathrm{Cu}$ nano-additives to the hardness and composition of DLC coatings in DLC/PAO solid-liquid composite lubricating system. Tribol Int 138: 184-195 (2019)

[22] Liu T T, Zhou C H, Gao C P, Zhang Y J, Yang G B, Zhang P Y, Zhang S M. Preparation of $\mathrm{Cu} @ \mathrm{SiO}_{2}$ composite nanoparticle and its tribological properties as water-based lubricant additive. Lubr Sci 32(2): 69-79 (2020)

[23] Chen Y F, Zhang Y J, Zhang S M, Yu L G, Zhang P Y, Zhang $\mathrm{Z}$ J. Preparation of nickel-based nanolubricants via a facile in situ one-step route and investigation of their tribological properties. Tribol Lett 51(1): 73-83 (2013)

[24] Zhao Z S, Zhang Y S, Wang S F, Guo K, Tang J, Wu Z G, Zhang G G, Zhu Y X, Yan P X, Zhang W Y. Tribological properties of oleylamine-modified nickel nanoparticles as lubricating oil additive. Mater Res Express 6(10): 105037 (2019)

[25] Chen L, Xu H Y, Cui H X, Zhou H D, Wan H Q, Chen J M. Preparation of $\mathrm{Cu}-\mathrm{Ni}$ bimetallic nanoparticles surface-capped with dodecanethiol and their tribological properties as lubricant additive. Particuology 34: 89-96 (2017)

[26] Zadoshenko E G, Burlakova V E, Novikova A A. Effect of nickel nanopowder on lubrication behaviour of lowtemperature grease in steel-steel tribosystem. Tribol - Mater 
Surfaces Interfaces 14(1): 51-58 (2020)

[27] Zhang S W, Li Y, Hu L T, Feng D P, Wang H Z. AntiWear effect of $\mathrm{Mo}$ and $\mathrm{W}$ nanoparticles as additives for multialkylated cyclopentanes oil in vacuum. J Tribol 139(2): 021607 (2017)

[28] Uflyand I E, Zhinzhilo V A, Burlakova V E. Metalcontaining nanomaterials as lubricant additives: State-ofthe-art and future development. Friction 7(2): 93-116 (2019)

[29] Uflyand I E, Zhinzhilo V A, Lapshina L S, Novikova A A, Burlakova V E, Dzhardimalieva G I. Conjugated thermolysis of metal chelate monomers based on cobalt acrylate complexes with polypyridyl ligands and tribological performance of nanomaterials obtained. ChemistrySelect 3(31): 8998-9007 (2018)

[30] Sanukrishna S S, Vishnu S, Krishnakumar T S, Jose Prakash M. Effect of oxide nanoparticles on the thermal, rheological and tribological behaviours of refrigerant compressor oil: An experimental investigation. Int J Refrig 90: 32-45 (2018)

[31] Hernández A, González R, Viesca J L, Fernández J E, Díaz Fernández J M, Machado A, Chou R, Riba J. CuO, $\mathrm{ZrO}_{2}$ and $\mathrm{ZnO}$ nanoparticles as antiwear additive in oil lubricants. Wear 265(3-4): 422-428 (2008)

[32] Zhou G H, Zhu Y F, Wang X M, Xia M J, Zhang Y, Ding $\mathrm{H}$ Y. Sliding tribological properties of $0.45 \%$ carbon steel lubricated with $\mathrm{Fe}_{3} \mathrm{O}_{4}$ magnetic nano-particle additives in baseoil. Wear 301(1-2): 753-757 (2013)

[33] Laad M, Jatti V K S. Titanium oxide nanoparticles as additives in engine oil. J King Saud Univ - Eng Sci 30(2): 116-122 (2018)

[34] Xia W Z, Zhao J W, Wu H, Zhao X M, Zhang X M, Xu J Z, Jiao S H, Wang X G, Zhou C L, Jiang Z Y. Effects of oil-in-water based nanolubricant containing $\mathrm{TiO}_{2}$ nanoparticles in hot rolling of 304 stainless steel. J Mater Process Technol 262: 149-156 (2018)

[35] Trivedi K, Parekh K, Upadhyay R V. Nanolubricant: Magnetic nanoparticle based. Mater Res Express 4(11): 114003 (2017)

[36] Bhaumik S, Maggirwar R, Datta S, Pathak S D. Analyses of anti-wear and extreme pressure properties of castor oil with zinc oxide nano friction modifiers. Appl Surf Sci 449: 277-286 (2018)

[37] Guo H J, Lu C, Zhang Z Y, Liang B N, Jia J H. Comparison of microstructures and properties of $\mathrm{VN}$ and $\mathrm{VN} / \mathrm{Ag}$ nanocomposite films fabricated by pulsed laser deposition. Appl Phys A 124(10): 1-8 (2018)

[38] Liu E Y, Bai Y P, Gao Y M, Yi G W, Jia J H. Tribological properties of NiAl-based composites containing $\mathrm{Ag}_{3} \mathrm{VO}_{4}$ nanoparticles at elevated temperatures. Tribol Int 80: 25-33 (2014)
[39] Zhu S Y, Bi Q L, Yang J, Liu W M. Tribological property of $\mathrm{Ni}_{3} \mathrm{Al}$ matrix composites with addition of $\mathrm{BaMoO}_{4}$. Tribol Lett 43(1): 55-63 (2011)

[40] Ye P P, Jiang X X, Li S, Li S Z. Preparation of $\mathrm{NiMoO}_{2} \mathrm{~S}_{2}$ nanoparticle and investigation of its tribological behavior as additive in lubricating oils. Wear 253(5-6): 572-575 (2002)

[41] Wang J H, Zhuang W P, Yan T T, Liang W F, Li T, Zhang L X, Wei X Y, Zhang L P. Preparation and tribological properties of calcium perrhenate as high-performance lubricating additive toward a broad temperature range. $J$ Mater Res Technol 9(3): 6579-6594 (2020)

[42] Wang J H, Li T, Yan T T, Wei X Y, Qu X, Yuan S. Friction behavior of silver perrhenate in oil as lubricating additive for use at elevated temperatures. Materials (Basel) 12(13): E2199 (2019)

[43] Wang J H, Liu Y, Duan D L, Li S. Comparative study on the tribological performances of Barium perrhenate, molybdenum disulfide, and calcium carbonate as lubricant additives in a wide temperature range. Tribol Trans 59(1): 139-148 (2016)

[44] Wang J H, Liu Y, Duan D L, Li S. Exploration on tribological behaviours of perrhenates as potential lubricating oil additive during a wide temperature range. Lubr Sci 27(7): 413-427 (2015)

[45] Ku B C, Han Y C, Lee J E, Lee J K, Park S H, Hwang Y J. Tribological effects of fullerene $\left(\mathrm{C}_{60}\right)$ nanoparticles added in mineral lubricants according to its viscosity. Int J Precis Eng Manuf 11(4): 607-611 (2010)

[46] Kalin M, Kogovšek J, Remškar M. Mechanisms and improvements in the friction and wear behavior using $\mathrm{MoS}_{2}$ nanotubes as potential oil additives. Wear 280-281: 36-45 (2012)

[47] Ye M T, Cai T, Zhao L N, Liu D, Liu S G. Covalently attached strategy to modulate surface of carbon quantum dots: Towards effectively multifunctional lubricant additives in polar and apolar base fluids. Tribol Int 136: 349-359 (2019)

[48] Huang H, Hu H L, Qiao S, Bai L, Han M M, Liu Y, Kang Z H. Carbon quantum $\operatorname{dot} / \mathrm{CuS}_{x}$ nanocomposites towards highly efficient lubrication and metal wear repair. Nanoscale 7(26): 11321-11327 (2015)

[49] Ma W, Gong Z B, Gao K X, Qiang L, Zhang J Y, Yu S R. Superlubricity achieved by carbon quantum dots in ionic liquid. Mater Lett 195: 220-223 (2017)

[50] Xiao H P, Liu S H, Xu Q, Zhang H. Carbon quantum dots: An innovative additive for water lubrication. Sci China Technol Sci 62(4): 587-596 (2019)

[51] Wang B G, Tang W W, Lu H S, Huang Z Y. Ionic liquid capped carbon dots as a high-performance friction-reducing and antiwear additive for poly(ethylene glycol). J Mater 
Chem A 4(19): 7257-7265 (2016)

[52] Ye M T, Cai T, Shang W J, Zhao L N, Zhang Y X, Liu D, Liu S G. Friction-induced transfer of carbon quantum dots on the interface: Microscopic and spectroscopic studies on the role of inorganic-organic hybrid nanoparticles as multifunctional additive for enhanced lubrication. Tribol Int 127: 557-567 (2018)

[53] Wang Z Q, Ren R R, Song H J, Jia X H. Improved tribological properties of the synthesized copper/carbon nanotube nanocomposites for rapeseed oil-based additives. Appl Surf Sci 428: 630-639 (2018)

[54] Gao T, Li C H, Zhang Y B, Yang M, Jia D Z, Jin T, Hou Y L, Li R Z. Dispersing mechanism and tribological performance of vegetable oil-based CNT nanofluids with different surfactants. Tribol Int 131: 51-63 (2019)

[55] Salah N, Abdel-Wahab M S, Alshahrie A, Alharbi N D, Khan $\mathrm{Z}$ H. Carbon nanotubes of oil fly ash as lubricant additives for different base oils and their tribology performance. RSC $A d v$ 7(64): 40295-40302 (2017)

[56] Ye X Y, E S, Fan M J. The influences of functionalized carbon nanotubes as lubricating additives: Length and diameter. Diam Relat Mater 100: 107548 (2019)

[57] Khalil W, Mohamed A, Bayoumi M, Osman T A. Tribological properties of dispersed carbon nanotubes in lubricant. Fuller Nanotub Car N 24(7): 479-485 (2016)

[58] Muzakkir S M, Lijesh K P, Hirani H. Influence of surfactants on tribological behaviors of MWCNTs (multi-walled carbon nano-tubes). Tribol - Mater Surfaces Interfaces 10(2): 74-81 (2016)

[59] Gong K L, Wu X H, Zhao G Q, Wang X B. Tribological properties of polymeric aryl phosphates grafted onto multiwalled carbon nanotubes as high-performances lubricant additive. Tribol Int 116: 172-179 (2017)

[60] Cornelio J A C, Cuervo P A, Hoyos-Palacio L M, LaraRomero J, Toro A. Tribological properties of carbon nanotubes as lubricant additive in oil and water for a wheel-rail system. J Mater Res Technol 5(1): 68-76 (2016)

[61] Peng Y T, Hu Y Z, Wang H. Tribological behaviors of surfactant-functionalized carbon nanotubes as lubricant additive in water. Tribol Lett 25(3): 247-253 (2007)

[62] Liu H T, Ji H M, Hong H P, Younes H. Tribological properties of carbon nanotube grease. Ind Lubr Tribol 66(5): 579-583 (2014)

[63] Duan W H, Wang Q, Collins F. Dispersion of carbon nanotubes with SDS surfactants: A study from a binding energy perspective. Chem Sci 2(7): 1407-1413 (2011)

[64] Sun X H, Zhao M, Han B, Kang H J, Fan Z M, Liu Y Y, Umar A, Guo Z H. Frictional reduction with partially exfoliated multi-walled carbon nanotubes as water-based lubricant additives. J Nanosci Nanotechnol 18(5): 3427-3432 (2018)

[65] Matsumura K, Chiashi S, Maruyama S, Choi J. Macroscale tribological properties of fluorinated graphene. Appl Surf Sci 432: 190-195 (2018)

[66] Huang Y H, Yao Q Z, Qi Y Z, Cheng Y, Wang H T, Li Q Y, Meng Y G. Wear evolution of monolayer graphene at the macroscale. Carbon 115: 600-607 (2017)

[67] Shi Z, Shum P, Wasy A, Zhou Z F, Li L K Y. Tribological performance of few layer graphene on textured M2 steel surfaces. Surf Coat Technol 296: 164-170 (2016)

[68] Kim H J, Shin D G, Kim D E. Frictional behavior between silicon and steel coated with graphene oxide in dry sliding and water lubrication conditions. Int J Precis Eng Manuf Green Technol 3(1): 91-97 (2016)

[69] Banerji A, Bhowmick S, Lukitsch M J, Alpas A T. Friction behaviour of multilayered graphene against steel. MRS Online Proc Libr 1812(1): 1-8 (2015)

[70] Zhao L, Cai Z B, Zhang Z C, Zhang X, Lin Y W, Peng J F, Zhu M H. Tribological properties of graphene as effective lubricant additive in oil on textured bronze surface. (in Chinese). Chin J Mater Res 30(1): 57-62 (2016).

[71] Senatore A, D'Agostino V, Petrone V, Ciambelli P, Sarno M. Graphene oxide nanosheets as effective friction modifier for oil lubricant: Materials, methods, and tribological results. ISRN Tribol 2013: 1-9 (2013)

[72] Mao J Y, Chen G Y, Zhao J, He Y Y, Luo J B. An investigation on the tribological behaviors of steel/copper and steel/steel friction pairs via lubrication with a graphene additive. Friction 9(2): 228-238 (2021)

[73] Li Y R, Zhao J, Tang C, He Y Y, Wang Y F, Chen J, Mao J Y, Zhou Q Q, Wang B Y, Wei F, et al. Highly exfoliated reduced graphite oxide powders as efficient lubricant oil additives. Adv Mater Interfaces 3(22): 1600700 (2016)

[74] Dou X, Koltonow AR, He X, Jang HD, Wang Q, Chung YW, Huang J. Self-dispersed crumpled graphene balls in oil for friction and wear reduction. PNAS 113(6): 1528-1533 (2016)

[75] Wu P, Chen X C, Zhang C H, Zhang J P, Luo J B, Zhang J Y. Modified graphene as novel lubricating additive with high dispersion stability in oil. Friction 9(1): 143-154 (2021)

[76] Kinoshita H, Nishina Y, Alias A A, Fujii M. Tribological properties of monolayer graphene oxide sheets as water-based lubricant additives. Carbon 66: 720-723 (2014)

[77] Lin J S, Wang L W, Chen G H. Modification of graphene platelets and their tribological properties as a lubricant additive. Tribol Lett 41(1): 209-215 (2011)

[78] Cai Z B, Zhao L, Zhang X, Yue W, Zhu M H. Combined effect of textured patterns and graphene flake additives on 
tribological behavior under boundary lubrication. PLoS One 11(4): e0152143 (2016)

[79] Hwang Y, Lee C, Choi Y, Cheong S, Kim D, Lee K, Lee J, Kim S H. Effect of the size and morphology of particles dispersed in nano-oil on friction performance between rotating discs. J Mech Sci Technol 25(11): 2853-2857 (2011)

[80] Lee C G, Hwang Y J, Choi Y M, Lee J K, Choi C, Oh J M. A study on the tribological characteristics of graphite nano lubricants. Int J Precis Eng Manuf 10(1): 85-90 (2009)

[81] Zhao J, Li Q Z, Li S X, Li S C, Chen G Y, Liu X H, He Y Y, Luo J B. Influence of a carbon-based tribofilm induced by the friction temperature on the tribological properties of impregnated graphite sliding against a cemented carbide. Friction 9(4): 686-696 (2021)

[82] Hirata A, Igarashi M, Kaito T. Study on solid lubricant properties of carbon Onions produced by heat treatment of diamond clusters or particles. Tribol Int 37(11-12): 899-905 (2004)

[83] Chu H Y, Hsu W C, Lin J F. The anti-scuffing performance of diamond nano-particles as an oil additive. Wear 268(7-8): 960-967 (2010)

[84] Wu P R, Li W, Feng Y M, Ge T, Liu Z, Cheng Z L. Fabrication and tribological properties of oil- soluble $\mathrm{MoS}_{2}$ nanosheets decorated by oleic diethanolamide borate. $J$ Alloys Compd 770: 441-450 (2019)

[85] Wang Y X, Du Y Y, Deng J N, Wang Z P. Friction reduction of water based lubricant with highly dispersed functional $\mathrm{MoS}_{2}$ nanosheets. Colloids Surfaces A: Physicochem Eng Aspects 562: 321-328 (2019)

[86] Tomala A, Ripoll M R, Kogovšek J, Kalin M, Bednarska A, Michalczewski R, Szczerek M. Synergisms and antagonisms between $\mathrm{MoS}_{2}$ nanotubes and representative oil additives under various contact conditions. Tribol Int 129: 137-150 (2019)

[87] Wu P R, Liu Z, Cheng Z L. Growth of $\mathrm{MoS}_{2}$ nanotubes templated by halloysite nanotubes for the reduction of friction in oil. ACS Omega 3(11): 15002-15008 (2018)

[88] Wu J, Mu L W, Zhu J H, Feng X, Lu X H, Larsson R, Shi Y J. Synthesis of hollow fullerene-like molybdenum disulfide/ reduced graphene oxide nanocomposites with excellent lubricating properties. Carbon 134: 423-430 (2018)

[89] Xu Y F, Geng J, Peng Y B, Liu Z C, Yu J Y, Hu X G. Lubricating mechanism of $\mathrm{Fe}_{3} \mathrm{O}_{4} @ \mathrm{MoS}_{2}$ core-shell nanocomposites as oil additives for steel/steel contact. Tribol Int 121: 241-251 (2018)

[90] Cheng L H, Hu E Z, Chao X Q, Zhu R F, Hu K H, Hu X G. $\mathrm{MoS}_{2} /$ montmorillonite nanocomposite: Preparation, tribological properties, and inner synergistic lubrication. Nano 13(12): 1850144 (2018)
[91] Yi M R, Zhang C H. The synthesis of $\mathrm{MoS}_{2}$ particles with different morphologies for tribological applications. Tribol Int 116: 285-294 (2017)

[92] Hu N N, Zhang X H, Wang X H, Wu N, Wang S Q. Study on tribological properties and mechanisms of different morphology $\mathrm{WS}_{2}$ as lubricant additives. Materials 13(7): 1522 (2020)

[93] Wu H X, Wang L P, Dong G N, Yang S C, Zhang J F, Zhou $B$, Tang Z Y. Lubrication effectiveness investigation on the friendly capped $\mathrm{MoS}_{2}$ nanoparticles. Lubr Sci 29(2): 115-129 (2017)

[94] Knirsch K C, Berner N C, Nerl H C, Cucinotta C S, Gholamvand Z, McEvoy N, Wang Z X, Abramovic I, Vecera $\mathrm{P}$, Halik M, et al. Basal-plane functionalization of chemically exfoliated molybdenum disulfide by diazonium salts. ACS Nano 9(6): 6018-6030 (2015)

[95] Kang S M, You I, Cho W K, Shon H K, Lee T G, Choi I S, Karp J M, Lee H. One-step modification of superhydrophobic surfaces by a mussel-inspired polymer coating. Angewandte Chemie 122(49): 9591-9594 (2010)

[96] Wu X H, Gong K L, Zhao G Q, Lou W J, Wang X B, Liu W $\mathrm{M} . \mathrm{MoS}_{2} / \mathrm{WS}_{2}$ quantum dots as high-performance lubricant additive in polyalkylene glycol for steel/steel contact at elevated temperature. Adv Mater Interfaces 5(1): 1700859 (2018)

[97] Gong K L, Lou W J, Zhao G Q, Wu X H, Wang X B. Investigation on tribological behaviors of $\mathrm{MoS}_{2}$ and $\mathrm{WS}_{2}$ quantum dots as lubricant additives in ionic liquids under severe conditions. Friction 8(4): 674-683 (2020)

[98] Li Z W, Hou X, Yu L G, Zhang Z J, Zhang P Y. Preparation of lanthanum trifluoride nanoparticles surface-capped by tributyl phosphate and evaluation of their tribological properties as lubricant additive in liquid paraffin. Appl Surf Sci 292: 971-977 (2014)

[99] Li S, Qin H J, Zuo R F, Bai Z M. Friction properties of La-doped $\mathrm{Mg} / \mathrm{Al}$ layered double hydroxide and intercalated product as lubricant additives. Tribol Int 91: 60-66 (2015)

[100] Li S, Qin H J, Zuo R F, Bai Z M. Tribological performance of $\mathrm{Mg} / \mathrm{Al} / \mathrm{Ce}$ layered double hydroxides nanoparticles and intercalated products as lubricant additives. Appl Surf Sci 353: 643-650 (2015)

[101] Zhao F Y, Bai Z M, Fu Y, Zhao D, Yan C M. Tribological properties of serpentine, $\mathrm{La}(\mathrm{OH})_{3}$ and their composite particles as lubricant additives. Wear 288: 72-77 (2012)

[102] Wang H D, Liu Y H, Liu W R, Wang R, Wen J G, Sheng H P, Peng J F, Erdemir A, Luo J B. Tribological behavior of NiAl-layered double hydroxide nanoplatelets as oil-based lubricant additives. ACS Appl Mater Interfaces 9(36): 30891-30899 (2017) 
[103] Wang H D, Liu Y H, Chen Z, Wu B B, Xu S L, Luo J B. Layered double hydroxide nanoplatelets with excellent tribological properties under high contact pressure as water-based lubricant additives. Sci Rep 6: 22748 (2016)

[104] Wang K P, Wu H C, Wang H D, Liu Y H, Yang L, Zhao L M. Tribological properties of novel palygorskite nanoplatelets used as oil-based lubricant additives. Friction 9(2): 332-343 (2021)

[105] Yu H L, Xu Y, Shi P J, Wang H M, Wei M, Zhao K K, Xu B S. Microstructure, mechanical properties and tribological behavior of tribofilm generated from natural serpentine mineral powders as lubricant additive. Wear 297(1-2): 802-810 (2013)

[106] Rudenko P, Bandyopadhyay A. Talc as friction reducing additive to lubricating oil. Appl Surf Sci 276: 383-389 (2013)

[107] Kumari S, Sharma OP, Khatri OP. Alkylamine-functionalized hexagonal boron nitride nanoplatelets as a novel material for the reduction of friction and wear. Phys Chem Chem Phys 18(33): 22879-22888 (2016)

[108] Kumari S, Sharma O P, Gusain R, Mungse H P, Kukrety A, Kumar N, Sugimura H, Khatri O P. Alkyl-chain-grafted hexagonal boron nitride nanoplatelets as oil-dispersible additives for friction and wear reduction. ACS Appl Mater Interfaces 7(6): 3708-3716 (2015)

[109] Deepika, Li LH, Glushenkov AM, Hait SK, Hodgson P, Chen Y. High-efficient production of boron nitride nanosheets via an optimized ball milling process for lubrication in oil. Sci Rep 4: 7288 (2014)

[110] Cho D H, Kim J S, Kwon S H, Lee C, Lee Y Z. Evaluation of hexagonal boron nitride nano-sheets as a lubricant additive in water. Wear 302(1-2): 981-986 (2013)

[111] Kwon O S, Lee D, Lee S P, Kang Y G, Kim N C, Song S H. Enhancing the mechanical and thermal properties of boron nitride nanoplatelets/elastomer nanocomposites by latex mixing. RSC Adv 6(65): 59970-59975 (2016)

[112] Boldrin L, Scarpa F, Chowdhury R, Adhikari S. Effective mechanical properties of hexagonal boron nitride nanosheets. Nanotechnology 22(50): 505702 (2011)

[113] Li X M, Yin J, Zhou J X, Guo W L. Large area hexagonal boron nitride monolayer as efficient atomically thick insulating coating against friction and oxidation. Nanotechnology 25(10): 105701 (2014).

[114] Çelik O N, Ay N, Göncü Y. Effect of nano hexagonal boron nitride lubricant additives on the friction and wear properties of AISI 4140 steel. Part Sci Technol 31(5): 501-506 (2013)

[115] Charoo M S, Wani M F. Tribological properties of h-BN nanoparticles as lubricant additive on cylinder liner and piston ring. Lubr Sci 29(4): 241-254 (2017)
[116] Wang Y N, Wan Z P, Lu L S, Zhang Z H, Tang Y. Friction and wear mechanisms of castor oil with addition of hexagonal boron nitride nanoparticles. Tribol Int 124: 10-22 (2018)

[117] Gupta M K, Bijwe J, Padhan M. Role of size of hexagonal boron nitride particles on tribo-performance of nano and micro oils. Lubr Sci 30(8): 441-456 (2018)

[118] de Joni I M, Balgis R, Ogi T, Iwaki T, Okuyama K. Surface functionalization for dispersing and stabilizing hexagonal boron nitride nanoparticle by bead milling. Colloids Surfaces A: Physicochem Eng Aspects 388(1-3): 49-58 (2011)

[119] Ma Z S, Ding H L, Liu Z, Cheng Z L. Preparation and tribological properties of hydrothermally exfoliated ultrathin hexagonal boron nitride nanosheets (BNNSs) in mixed NaOH/KOH solution. J Alloys Compd 784: 807-815 (2019)

[120] Bai Y Q, Zhang J, Wang Y F, Cao Z Y, An L L, Zhang B, Yu Y L, Zhang J Y, Wang C M. Ball milling of hexagonal boron nitride microflakes in ammonia fluoride solution gives fluorinated nanosheets that serve as effective waterdispersible lubricant additives. ACS Appl Nano Mater 2(5): 3187-3195 (2019)

[121] Wang H D, Liu Y H. Superlubricity achieved with twodimensional nano-additives to liquid lubricants. Friction 8(6): 1007-1024 (2020)

[122] Meng Y G, Xu J, Jin Z M, Prakash B, Hu Y Z. A review of recent advances in tribology. Friction 8(2): 221-300 (2020)

[123] Tang G B, Su F H, Xu X, Chu P K. 2D black phosphorus dotted with silver nanoparticles: An excellent lubricant additive for tribological applications. Chem Eng $J$ 392: 123631 (2020)

[124] Wang W, Xie G X, Luo J B. Black phosphorus as a new lubricant. Friction 6(1): 116-142 (2018)

[125] Wu S, He F, Xie G, Bian Z, Luo J, Wen S. Black phosphorus: Degradation favors lubrication. Nano Lett 18(9): 5618-5627 (2018)

[126] Lv Y, Wang W, Xie G X, Luo J B. Self-lubricating PTFEbased composites with black phosphorus nanosheets. Tribol Lett 66(2): 1-11 (2018)

[127] Illarionov Y Y, Waltl M, Rzepa G, Knobloch T, -S Kim J, Akinwande D, Grasser T. Highly-stable black phosphorus field-effect transistors with low density of oxide traps. $N p j$ 2D Mater Appl 1: 23 (2017)

[128] Walia S, Balendhran S, Ahmed T, Singh M, El-Badawi C, Brennan M D, Weerathunge P, Karim M N, Rahman F, Rassell A, et al. Black phosphorus: Ambient protection of few-layer black phosphorus via sequestration of reactive oxygen species (Adv. Mater. 27/2017). Adv Mater 29(27): DOI 10.1002/adma.201770197 (2017) 
[129] Hu Z H, Li Q, Lei B, Wu J, Zhou Q H, Gu C D, Wen X L, Wang J Y, Liu Y P, Li S S, et al. Abnormal near-infrared absorption in 2D black phosphorus induced by $\mathrm{Ag}$ nanoclusters surface functionalization. Adv Mater 30(43): 1801931 (2018)

[130] Wang W, Xie G X, Luo J B. Superlubricity of black phosphorus as lubricant additive. ACS Appl Mater Interfaces 10(49): 43203-43210 (2018)

[131] Ren X Y, Yang X, Xie G X, Luo J B. Black phosphorus quantum dots in aqueous ethylene glycol for macroscale superlubricity. ACS Appl Nano Mater 3(5): 4799-4809 (2020)

[132] Meng Y, Su F H, Chen Y Z. Effective lubricant additive of nano-Ag/MWCNTs nanocomposite produced by supercritical $\mathrm{CO}_{2}$ synthesis. Tribol Int 118: 180-188 (2018)

[133] Xiong S, Zhang B S, Luo S, Wu H, Zhang Z. Preparation, characterization, and tribological properties of silicananoparticle-reinforced B-N-co-doped reduced graphene oxide as a multifunctional additive for enhanced lubrication. Friction 9(4): 239-249 (2021)

[134] Gong K L, Lou W J, Zhao G Q, Wu X H, Wang X B. $\mathrm{MoS}_{2}$ nanoparticles grown on carbon nanomaterials for lubricating oil additives. Friction 9(4): 747-757 (2021)

[135] Ren B J, Gao L, Xie B T, Li M J, Zhang S D, Zu G Q, Ran $X$. Tribological properties and anti-wear mechanism of $\mathrm{ZnO@graphene} \mathrm{core-shell} \mathrm{nanoparticles} \mathrm{as} \mathrm{lubricant}$ additives. Tribol Int 144: 106114 (2020).

[136] Hou X, Yang C Z, He J, Li Z W, Zhang Z J. Preparation and tribological properties of lanthanum trifluoride nanoparticles-decorated graphene oxide nanosheets. Ind Eng Chem Res 54(17): 4773-4780 (2015)

[137] Yang C Z, Hou X, Li Z W, Li X H, Yu L G, Zhang Z J. Preparation of surface-modified lanthanum fluoride-graphene oxide nanohybrids and evaluation of their tribological properties as lubricant additive in liquid paraffin. Appl Surf Sci 388: 497-502 (2016).

[138] Zheng X J, Xu Y F, Geng J, Peng Y B, Olson D, Hu X G. Tribological behavior of $\mathrm{Fe}_{3} \mathrm{O}_{4} / \mathrm{MoS}_{2}$ nanocomposites additives in aqueous and oil phase media. Tribol Int 102: 79-87 (2016).

[139] Irtegov Y, An V, Machekhina K, Lemachko N. Influence of copper nanoparticles on tribological properties of nanolamellar tungsten disulfide. Key Eng Mater 712: 133-136 (2016).

[140] Wu B, Song H, Li C, Song R H, Zhang T M, Hu X G. Enhanced tribological properties of diesel engine oil with Nano-Lanthanum hydroxide/reduced graphene oxide composites. Tribol Int 141: 105951 (2020).

[141] Wang L, Gong P W, Li W, Luo T, Cao B Q. Mono-dispersed
$\mathrm{Ag} / \mathrm{Graphene}$ nanocomposite as lubricant additive to reduce friction and wear. Tribol Int 146: 106228 (2020).

[142] Min C Y, He Z B, Liu D D, Zhang K, Dong C K. Urea modified fluorinated carbon nanotubes: unique self-dispersed characteristic in water and high tribological performance as water-based lubricant additives. New J Chem. 43(37): 14684-14693 (2019).

[143] Zhao J H, Yang G B, Zhang C L, Zhang Y J, Zhang S M, Zhang P Y. Synthesis of water-soluble $\mathrm{Cu}$ nanoparticles and evaluation of their tribological properties and thermal conductivity as a water-based additive. Friction 7(3): 246-259 (2019)

[144] Peña-Parás L, Taha-Tijerina J, García A, Maldonado D, González J A, Molina D, Palacios E, Cantú P. Antiwear and extreme pressure properties of nanofluids for industrial applications. Tribol Trans 57(6): 1072-1076 (2014)

[145] Rahmati B, Sarhan A A D, Sayuti M. Morphology of surface generated by end milling AL6061-T6 using molybdenum disulfide $\left(\mathrm{MoS}_{2}\right)$ nanolubrication in end milling machining. J Clean Prod 66: 685-691 (2014)

[146] Duan G B, Hu X L, Song X Y, Qiu Z W, Gong H B, Cao $\mathrm{B}$ Q. Morphology evolution of $\mathrm{ZnO}$ submicroparticles induced by laser irradiation and their enhanced tribology properties by compositing with $\mathrm{Al}_{2} \mathrm{O}_{3}$ nanoparticles. $A d v$ Eng Mater 17(3): 341-348 (2015).

[147] Jatti V S, Singh T P. Copper oxide nano-particles as friction-reduction and anti-wear additives in lubricating oil. J Mech Sci Technol 29(2): 793-798 (2015)

[148] Liu L C, Zhou M, Jin L, Li L C, Mo Y T, Su G S, Li X, Zhu H W, Tian Y. Recent advances in friction and lubrication of graphene and other 2D materials: Mechanisms and applications. Friction 7(3): 199-216 (2019)

[149] Konicek A R, Jacobs P W, Webster M N, Schilowitz A M. Role of tribofilms in wear protection. Tribol Int 94: 14-19 (2016)

[150] Ahmed Ali M K, Hou X J, Essa F A, Abdelkareem M A A, Elagouz A, Sharshir S W. Friction and wear reduction mechanisms of the reciprocating contact interfaces using nanolubricant under different loads and speeds. $J$ Tribol 140(5): 051606 (2018).

[151] Ali M K A, Hou X J, Mai L Q, Chen B C, Turkson R F, Cai Q P. Reducing frictional power losses and improving the scuffing resistance in automotive engines using hybrid nanomaterials as nano-lubricant additives. Wear 364-365: 270-281 (2016)

[152] Zulkifli N W M, Kalam M A, Masjuki H H, Yunus R. Experimental analysis of tribological properties of biolubricant with nanoparticle additive. Procedia Eng 68: 152-157 (2013) 
[153] Asrul M, Zulkifli N W M, Masjuki H H, Kalam M A. Tribological properties and lubricant mechanism of nanoparticle in engine oil. Procedia Eng 68: 320-325 (2013)

[154] Alimirzaloo V, SheydayiGurchinQaleh S, MashhadiKeshtiban $\mathrm{P}$, Ahmadi S. Investigation of the effect of $\mathrm{CuO}$ and $\mathrm{Al}_{2} \mathrm{O}_{3}$ nanolubricants on the surface roughness in the forging process of aluminum alloy. Proc Inst Mech Eng Part J: J Eng Tribol 231(12): 1595-1604 (2017)

[155] Kheireddin B A, Lu W, Chen I C, Akbulut M. Inorganic nanoparticle-based ionic liquid lubricants. Wear 303(1-2): 185-190 (2013).

[156] Alves S, Mello V S, Sinatora A. Nanolubrication mechanisms: Influence of size and concentration of $\mathrm{CuO}$ nanoparticles. Mater Perform Charact 7(3): 226-241 (2018).

[157] Shafi W K, Raina A, Ul Haq M I. Friction and wear characteristics of vegetable oils using nanoparticles for sustainable lubrication. Tribol - Mater Surfaces Interfaces 12(1): 27-43 (2018)

[158] Luo T, Wei X W, Zhao H Y, Cai G Y, Zheng X Y. Tribology properties of $\mathrm{Al}_{2} \mathrm{O}_{3} / \mathrm{TiO}_{2}$ nanocomposites as lubricant additives. Ceram Int 40(7): 10103-10109 (2014)

[159] Liu Y H, Xin L, Zhang Y J, Chen Y F, Zhang S M, Zhang $\mathrm{P} Y$. The effect of Ni nanoparticles on the lubrication of a DLC-based solid-liquid synergetic system in all lubrication regimes. Tribol Lett 65(2): 1-9 (2017)

[160] Dai W, Kheireddin B, Gao H, Liang H. Roles of nanoparticles in oil lubrication. Tribol Int 102: 88-98 (2016)

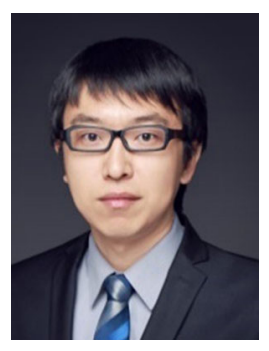

Junhai WANG. He is an associate professor in the School of Mechanical Engineering at Shenyang Jianzhu University. He received his Ph.D. degree in the Institute

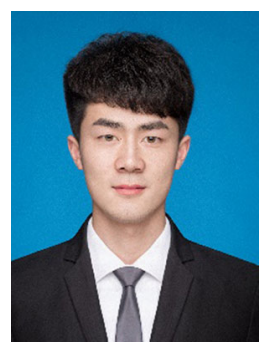

Weipeng ZHUANG. He received his B.S. degree in 2019 from Chongqing Jiaotong University, Chongqing, China. He is now a candidate for
[161] Wu L L, Zhang Y J, Yang G B, Zhang S M, Yu L G, Zhang P Y. Tribological properties of oleic acid-modified zinc oxide nanoparticles as the lubricant additive in poly-alpha olefin and diisooctyl sebacate base oils. RSC $A d v$ 6(74): 69836-69844 (2016)

[162] Dinesh R, Prasad M J G, Kumar R R, Santharaj N J, Santhip J, Raaj A S A. Investigation of tribological and thermophysical properties of engine oil containing nano additives. Mater Today: Proc 3(1): 45-53 (2016)

[163] Koshy C P, Rajendrakumar P K, Thottackkad M V. Evaluation of the tribological and thermo-physical properties of coconut oil added with $\mathrm{MoS}_{2}$ nanoparticles at elevated temperatures. Wear 330-331: 288-308 (2015)

[164] Azman N F, Samion S, Mat Sot M. Investigation of tribological properties of $\mathrm{CuO} /$ palm oil nanolubricant using pin-on-disc tribotester. Green Mater 6(1): 30-37 (2018).

[165] He Q, Li A L, Zhang Y M, Liu S F, Guo Y C. Experimental study of tribological properties of lithium-based grease with $\mathrm{Cu}$ nanoparticle additive. Tribol - Mater Surfaces Interfaces 11(2): 75-82 (2017)

[166] Wu H, Zhao J W, Xia W Z, Cheng X W, He A S, Yun J H, Wang L Z, Huang H, Jiao S H, Huang L, et al. A study of the tribological behaviour of $\mathrm{TiO}_{2}$ nano-additive water-based lubricants. Tribol Int 109: 398-408 (2017)

[167] Lijesh K P, Muzakkir S M, Hirani H. Experimental tribological performance evaluation of nano lubricant using multi-walled carbon nano-tubes (MWCNT). Int $J$ Appl Eng Res 10(6): 14543-14550 (2015)

of Metal Research, Chinese Academy of Sciences, in 2015. His research involves the design of advanced lubricating additive, self-lubrication multilayer coatings, and surface modification technology.

master degree in the School of Mechanical Engineering, Shenyang Jianzhu University. His research interest is nano-scale lubricating additives. 


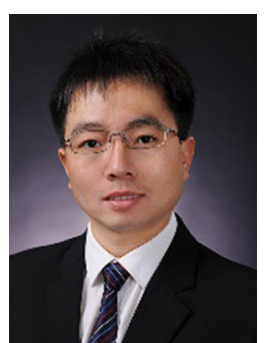

Wenfeng LIANG. He received his Ph.D. degree in mechatronic engineering from Shenyang Institute of Automation, Chinese Academy of Sciences, in 2014. From 2014 to

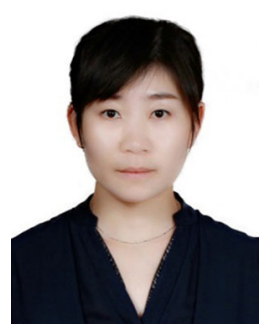

Tingting YAN. She is an associate professor in Shenyang Jianzhu University. She received her Ph.D. degree in condensed matter physics from Jilin University in 2015. She

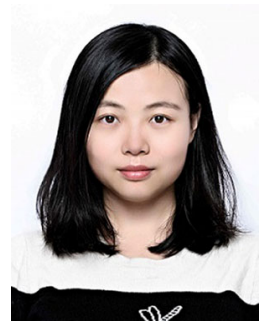

Ting LI. She is an associate professor in the School of Mechanical Engineering at Shenyang Jianzhu University. She received his Ph.D.

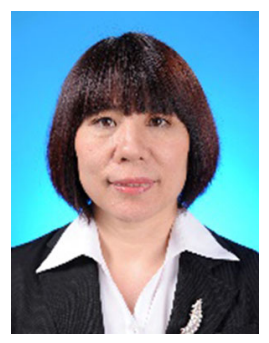

Lixiu ZHANG. She is a professor in the School of Mechanical Engineering, Shenyang Jianzhu University. She received her Ph.D. degree in mechanical manufacturing

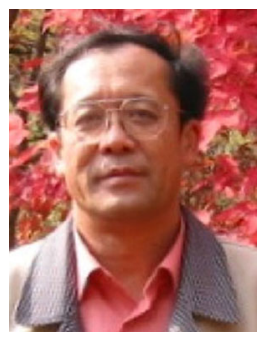

Shu LI. He is a professor in the Institute of Metal research, Chinese Academy of Sciences. He received his Ph.D. degree in materials science from the Institute of Metal research,
2017, he was a postdoctoral researcher in the Shenyang Institute of Automation. Since 2014, he has become a faculty member of Shenyang Jianzhu University. His research interests lie in nanomaterials as well as fabrication of micro/nano tribology.

was a visiting scholar in Texas Tech University in USA in 2019. Her research fields cover changes in the structure and properties of lubricating materials and design of the structure of nanomaterials.

degree (2014) from Wuhan University, China. Her research covers the design of advanced functional film, nanomaterials, and tribo-corrosion.

and automation from Dalian University of Technology in 2012. Her research interests include nano-additives, tribology, heat transfer, and ceramic bearing. She has published more than 100 peer reviewed journal papers.

Chinese Academy of Sciences, in 2001. His research areas cover the advanced lubricating oil additive design as well as tribological behaviors of engineering materials under severe conditions. 